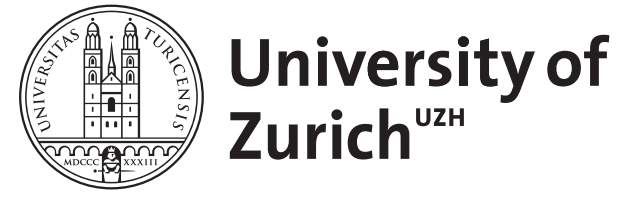

Zurich Open Repository and Archive

University of Zurich

University Library

Strickhofstrasse 39

CH-8057 Zurich

www.zora.uzh.ch

Year: 2007

\title{
Introduction: through contexts to actions
}

Leist, Anton

DOI: https://doi.org/10.1515/9783110898798.1

Posted at the Zurich Open Repository and Archive, University of Zurich

ZORA URL: https://doi.org/10.5167/uzh-55324

Book Section

Published Version

Originally published at:

Leist, Anton (2007). Introduction: through contexts to actions. In: Leist, A. Action in Context. Berlin/New York: De Gruyter, 1-52.

DOI: https://doi.org/10.1515/9783110898798.1 


\title{
Introduction: Through Contexts to Actions
}

\author{
Anton Leist
}

\section{Action in Context: Why not Holism in the Theory of Action?}

In one of his last articles, D. Davidson pointed out the remarkable fact that in the history of (Western) philosophy there have been only two periods of pronounced interest in what actions are-as opposed to the usual, moral interest in how we ought to act-, namely in Aristotle's time and the present day (Davidson 2005, 277). This observation could be complemented by another: it is perhaps no coincidence that during Aristotle's period of thought, as in current philosophy, traditional enthusiasm for metaphysics and epistemology was and is counterbalanced by a critical distance towards these disciplines, so that in the resulting philosophical pluralism, in addition to the pervading interest in all aspects of knowledge and the mind, it was and is possible to take an extensive look at actions. In actual fact, a wealth of literature and discussion covering an independent discipline known as 'action theory' has been open to 'analytic philosophers' for decades, but the fact that this discipline is a speciality alongside many others already underlines the theoretically ambivalent and uncertain role of action theory within the context of philosophy taken as a whole. The traditional quibbles concerning language, mind and consciousness continue to loom more heavily than such small-scale quandaries surrounding why and how human beings act.

If it is true that action theory has been pushed into a specific box by other disciplines, it is also true that it has not been overwhelmingly enthusiastic to enlarge upon its specific topic. For Davidson and the representative parts of analytic action theory he has influenced, "what actions are" is the central issue which upon second glance is typically not as harmless as it first appears. What actions are, or what constitutes an action, is usually viewed as the central question of action theory, usually phrased with the help of Wittgenstein's formulation: "What is left over if I subtract the fact that my arm goes up from the fact that I raise my arm?" (PU, I. \$621) Many authors have accepted this question as the central 
question $^{1}$ and quite a lot have taken up Davidson's agenda and tried to elaborate actions under his central idea that belief and desire simultaneously rationalise an action and causally produce or explain it. $^{2}$ Davidson himself admitted that his proposal contained a number of problem spots and open angles, but he continued to support it right up until he ceased to write (see Davidson 2001).

Davidson and others have connected the standard model of action theory with two insights in particular, both adopted from Wittgenstein and Anscombe: firstly, that actions have to be identified via descriptions and that descriptions of one and the same action form an open set; secondly, that the subjective states of the agent have to rationalise an action and that, correspondingly, the action can be explained as rationally comprehensible. Davidson's specific achievement is usually regarded as having successfully reconciled these two requirements with a third which previously, in the intellectual climate of Ryle and Wittgenstein, had appeared to be incompatible with them: the hypothesis of a causal relationship, as opposed to a logical-conceptual one, existing between the motives behind an action and the action itself. Until today, the attractiveness of this project, started by Davidson in 1963, lies in its awe-inspiring claim to facilitating a connection between these three requirements: dependency on description, rationalisation and causality.

Enthusiasm is being dulled, however, by the strange narrowness of this agenda, already apparent in the 'central question'. Whereas, in his linguistic theory, Davidson supports an unrestricted holism, with individual sentences acquiring their meaning from the meanings of all the other sentences of a language (Davidson 1984, essays 9-12), actions are grasped and understood more narrowly. Despite fundamentally conceding a mutual dependency between meanings, desires and beliefs, and despite accepting the dependency of actions upon descriptions, he

1 For variations on the 'central question' of action theory, see M. Brand: "to adequately specify the nature of the proximate cause of action" (Brand 1984, 33). Or H. Frankfurt: "The problem of action is to explicate the contrast between what an agent does and what merely happens to him, or between the bodily movement that he makes and those that accur without his making them." (Frankfurt 1978, 157). Also Velleman 2000, chap. 1.

2 The belief-desire model of action plays a dominant role not only in action theory, but also in the explication of practical reasons (Anscombe, von Wright, M. Smith) and in metaethics (Hare), as well as in the social sciences. Its historical forebears are Plato (Phaidros, Politeia), Aristotle (De Anima 433a, NE Book 3), Hobbes (Leviathan, chap. 6) and Hume (Treatise II.3.iii). 
remained in consistent pursuit of an action model which was more reductive than holistic. Instead of viewing both the description and the rationality of actions as dependent upon the description of many other things (the agent, his self-comprehension, his attitude, his knowledge, his history, his circumstances, his social position and role, his society, his tradition, etc.), comprehension of actions is reduced to a comprehension of descriptions of individual events. Not only is this ontologically emaciated version of action theory barely compatible with Davidson's own increasingly detailed hermeneutic agenda (Malpas 1992), it is also no longer tenable in the light of numerous objections which have been put forward over the past few years.

What happens when we act can certainly be described with the help of psychological states and events, but also equally well with the help of attitudes, memories, plans, phases in agents' lives and their life-stories. It can be explained by referring to the immediate beliefs and desires of the agents, but also by referring to the beliefs and knowledge of the community, the argumentative standards of those communicating. It can be viewed both in the light of individual characteristics and in the light of social expectations and norms, under the individual claim of convictions, but also under the aspect of normative opinions and collective beliefs. Actions can be dealt with as individual actions, but also as parts of collective actions. The intentions which are connected to a certain action can be made clear enough by that individual action, but in some circumstances may not be decipherable until a comprehensive tale has been told. Why should we think that all actions are equal and, more to the point, that they are all equally simple? Like all human manifestations, acting can be simple, but it can also be very complicated, and the advantage of holism lies in its acceptance of this complexity, presupposed even for the most basic elements of acting. One could only speak of a 'holistic' theory of action if the dependencies hinted at above were to become visible, whereas the standard theory of action has done its best to suppress them.

The 'standard theory' of action explains individual actions by using the rationalising relation between beliefs, desires and (in part) intentions with action-events. Current debates pursue various goals with regard to the standard theory, something I shall make more explicit in the next sections by giving an overview of diverse problems. Such critical discussions can, or so it appears, have the following three effects. Corrections intend to reconstruct in an alternative way the interior structure of acting with regard to its rationality, causality or intentionality 
assumptions, whilst retaining the standard model itself. A revision of the model is imminent when some of the taken views on acting - for example views concerning the relations between reasons and actions or the agent and his action-withstand elaboration. Expansions are possible when actions are studied in their relationships to various additional contexts which are relevant for the comprehension of those individual actions but unclear in their functional role so far. In my opinion, the debate within action theory is currently in the second phase. Perhaps the contributions to this book could elucidate this and possibly encourage a transition into the third phase.

'Action in Context' suggests that something which is already knownan action-is, as it were, experimentally pursued and illuminated in contexts and correlations independent of this action, partly due to interest in the action and partly due to interest in the contexts and correlations. Some devote themselves to study, for example, how normally valid assumptions within the standard action theory change when the environment changes (e.g. Bratman 1999a). Others see themselves in Dewey's pragmatic (and perhaps Darwinian) tradition, observing actions basically as reactions to pre-given situations, and thus never being without context (e.g. Stoutland 1998; 2001; Bittner 2001, 68-71). These attempts are particularly fruitful when they are made in a conscious effort to revise the fundamental concepts of action themselves and to formulate them more openly. ${ }^{3}$

If Davidson's holism for descriptions is correct and can be transferred equally to actions and the meaning of sentences in general, these attempts must lead to a continuing reformulation of action descriptions, individually and in general. Caught up in the hermeneutic circle, one can only speak of the 'context' of acting using a previously identified action-but at the same time the context also facilitates a new and extended description of the action. Even if actions were only materially detectable 'atoms', they could in each case be redescribed. Since they (unlike physical atoms) play differently complex functions in different personal and social contexts, their semantic contexts are even more

3 It goes without saying that there is quite some interest among empirical researchers in the social preconditions, both diachronic and synchronic, of single actions and the style of actions. Well-known present-day contributors to such a 'frame analysis' are the sociologists H. Esser and S. Lindenberg. Philosophy of action unduly neglects this research because of its still being bewitched by the 'concept' of action. 
important. The line of argument followed in this introduction could, rather than using the action/context distinction, equally well be described as a plea for action holism, for externalism or for the social normativity of conditions for action. Rather than setting a fixed idea of action into a fixed idea of context and looking out for interrelations, this is an attempt to open up perspectives on actions, and then perhaps make visible the importance of action for other topics as well.

\section{Standard Theory of Action: Basic Questions and Intriguing Answers}

On the condition of this inevitable circle, our talk of individual actions requires a wealth of background knowledge. One obvious possibility in the light of this dependency would be to describe, or at least to outline, the background necessary to individual actions. It would be reasonable to talk first of agents, rules, expectations, shared knowledge, the body, etc., and then about individual intentions, hand movements, spilled coffee, sunken ships, etc. The analytic theory of action married to Wittgenstein's 'basic question' did not proceed like this, possibly out of fear that this procedure would involve a damaging circle, as well as, incidentally, an unnecessary digression. In actual fact, it is impossible to speak of agents without actions-but the reverse is also true: working with a simple notion of action can be a useful method to enter the circle at a certain point as well, albeit not the only method.

What I call the 'standard theory' of action, in agreement with much of the literature, delivers just such a model of simplicity, which surely is helpful to make oneself acquainted with the multivarious aspects of actions and acting. The standard theory describes actions as a complex mixture of beliefs, desires and the execution of actions, and explains the latter as causing by rationalising through a 'primary' reason (primary in relation to possible other reasons), itself being a compound of belief and desire. This description and explanation of actions is not only outwardly impressively simple, it also excels by creating particularly intelligent answers to really difficult questions. And it is capable of linking different ontological, theoretical and practical dimensions. ${ }^{4}$ Just how good the

4 Because Davidson (1980) raised this synthetic view most strongly and put forward the most innovative contributions, in the following treatment I shall refer primarily to the debate he triggered. The terminology used thus far has already been taken from Davidson. Within the framework of his writing, 
answers are, especially in Davidson's original version, can only be properly appreciated after taking a brief look at the situation before Davidson's programmatic article appeared.

The difficulties surrounding action theory prior to Davidson were primarily located in two areas: firstly a lack of clarity regarding the roles of desire and intention, and secondly scepticism regarding the function of causality within action (see Thalberg 1985, esp. 9-16). As the last in a long series of attempts to unite mind and body, intention and causality, desire and control, J. St. Mill advocated the notion of action as a combination of desire and physical effect, yet leaving open the mutual relationship between the two. In this situation, three solution strategies became dominant, all three of which encountered massive problems within a short space of time. ${ }^{5}$

Firstly, what could be called the 'volition position'. In order to avoid the incoherence of radically different actions, mental as well as physical, Prichard declared only acts of will to be actions, with physical movements being their effects. This radical solution created more difficulties than it dispelled. Behind what we had so far taken to be ordinary actions were now, suddenly, countless previously unnoticed acts of will possessing a dubious status with regard to action. Ryle rendered this apparent in his well-known cutting and witty manner by combining them with attributes ("quickly", "simply", "enjoyably") for normal actions (Ryle 1949, chap. 3; Anscombe 1957, 47, 49). This and later critiques of other versions of Prichard's proposal-'tryings' rather than acts of will (Hornsby 1980; O'Shaughnessy 1980)—showed the reducibility of actions to acts of will to be an awkward solution.

Secondly, the position of 'agent' or 'perpetrator causality'. Rather than in a mental act, action is seen as being based on the agent and his

'standard theory' always means the basic model of 1963 and its immediate extensions (Davidson 1980, essays 1-3). The later revisions, especially in 'Intending' (1975), will be mentioned later on. There are controversial opinions concerning the extent in which Davidson grew to deviate from the standard theory, including Stoutland's 1999 argument for a nearly total split. For other versions of the standard model see Dretske 1988; Seebaß 1993, 144-160; Smith 1987. M. Smith is the most important defender of desires as practical reasons. I shall address this in detail in section 5 .

5 For overviews and references regarding the historic and contemporary literature on these three positions, see Thalberg 1985 and Seebaß 1993, 49-68. For a critique of Hornsby's and O'Shaugnessy's elaborations on the will see Seebaß 1993, 256. Donagan 1981 outlines the classical history of action theory up to Davidson. 
bringing forth of the action, a proposal which strangely enough is emerging again in the current debate under the label 'agency' (see section 6 below). Defended especially by Chisholm, this proposal encountered the problem of an independent and exotic concept of causality incompatible with event causality. Agent activity neglected in the standard theory but now rediscovered therefore has to be developed without the claim of being an ontologically independent form of causality.

Thirdly, there was what came to be called the logical 'reasons/causes dichotomy'. In brief this refers to the tendency of Wittgensteinians (Anscombe, Melden, von Wright, Stoutland) to focus on action rationality and the reasons justifying the agent, and from this practical perspective to prove that the causal explanation of actions is secondary or even impossible. The dichotomy began to look like a kind of dualism when Davidson was in turn able to introduce the expectation that practical reasons for an action would also have to generate it, or that actions would somehow have to be causally aroused in order to fit into the general causal fabric, a notion which was (and still is) alien to the followers of Wittgenstein. Whether dualism or not, whether causality relevant or not, the question of the relationship between reasons and causes was not satisfactorily answered from their side.

Compared to these three problematic strategies and models, the (Davidsonian) standard theory is impressive for its simplicity, rendering it apparently better able to answer a series of central questions pertaining to individual actions. Here is a short outline of these questions and answers. Firstly, when is an action 'basic' in the sense that it cannot be broken down into other actions? The answer is: if one is doing something not done by doing something else. Normally, but not necessarily always these basic actions are bodily movements. Bodily movements are events and thus potential candidates for causal relationships. Bodily movements are caused by primary reasons (beliefs/desires) which in turn are not actions. Bodily movements, beliefs, desires, causes and effects thus seem to enter into a conceptually fitting and homogenous relationship-extravagances like acts of will as actions sui generis, intrinsic-causal agent activities or causally isolated reasons become superfluous.

Secondly, how is the relationship between intentions and actions to be more precisely understood? The answer is: despite first appearances, intentions are not independent acts or events, but structural features of the relationship between primary reason and action. Intentions are thus indirectly linked to the causal events behind an action, find themselves in 
an indirect causal relationship to the action and not simply in a logical one, as postulated by the 'logical connection argument'. Not all actions are intentional actions, but non-intentional (unsuccessful, unwanted) actions are dependent upon intentional ones, thus only exist by dint of an intentional action.

Thirdly, how does the standard theory explain the possible diversity of action descriptions for one action? If actions are fundamentally bodily movements and events (both itself under a description), they can be described as such in different ways, so that different descriptions present different actions, without the bodily movement thereby causing different simultaneous actions. Bodily movement as a basic action provides, as it were, the material basis to which the most diverse-in principle an unlimited number of - action descriptions (and in this sense also actions) relate. Using a concept taken from J. Feinberg, a bodily movement (flicking a switch) gives rise to an 'accordion effect'-production of partly intentional actions (turning on a light) and partly unintentional ones (alerting a prowler).

Fourthly, can reasons for an action be simultaneously rational and motivating? Are these functions not mutually exclusive? And, if not, how can the rational reason motivate; how can the motivating reason be rational? The answer is: motives are rationalizing when they suitably adhere to beliefs, especially the belief that the action is suited to fulfilling a desire. When linked, beliefs and desires can therefore be both rationalising and motivating. This does not necessarily mean that there are no additional reasons; what is important is that every action arises from a primary reason of a combination of beliefs and desires. The somewhat narrow expression "desires" can be replaced by the term "proattitude", encompassing all possible forms of a mental propensity to act. A pro-attitude, that is a consenting stance towards an action, seems to be essential to each and every action.

And finally, fifthly, how can reasons be causes or be linked to them? Not necessarily through plain identity, but so that reasons are comprehended as linguistic descriptions of those causal and material events which cause another event. The description is the primary reason, the cause is an event of consciousness and the effect is the action as a material event. Primary reasons are thus indirectly both reasons and causes, and they are only causes because they are reasons, viz. can only be reasons for actions because they are causes. ${ }^{6}$

6 For a more detailed account, which especially demonstrates why action ex- 
Beyond the valid reasons for an action, causality seems to be indispensable, confirmed by the observation that an agent can have several reasons for an action, but acting out of one special reason. Only if the 'because' of one or other reason is a causal 'because', can one be sufficiently certain as to why one is actually acting or has acted. But then reasons for action can not only be linguistic entities, can not only belong to the 'logical realm of reasons', but also actually have to bring about actions causally, within the 'material realm of events'. Reasons must at the same time be able to justify and explain, and this includes their causal effectiveness.

If one accepts my portrayal of the historical situation, in which action theory had to choose between different radical positions (acts of will, agent causality, acausal reasons), the strength of the standard theory becomes obvious, resulting from its reaction to these options. Paramount is its response to the reasons/causes problem and the coherence of causality and action (see Mele 2003). Nevertheless, these gains in presumed coherence come at the price of doubts as to whether the phenomenal wealth of the earlier debate has really been captured by the Gordian knot proposal of the standard theory and as to whether new, even more pressing problems have not been created in the process. These doubts lead, on the one hand, to the objection that this theory portrays actions too simply and, on the other hand, to criticism of the distorting role of causality in the view of actions held by the standard theory. I shall start by depicting these problems more explicitly (section 3), then in turn sketch three attempts at solving them (sections 4-6).

\section{New Problems}

A representative overview of the problems and fields of discussion surrounding the standard theory may be thought to include at least the following central points from the standard theory and/or problems typically classified accordingly. ${ }^{7}$

planations, because they carry on where descriptions leave off, are not causal in the sense of law-dependent explanations but merely empirical-inductive explanations, see Stoutland 1999; Davidson 1987.

7 For illuminating and succinct critiques of the standard model, see Frankfurt 1978; Thalberg 1985; Stoutland 1985; 1998; 2001; Bratman 1985; Mele 1992; Hornsby 1993; Stout 1996; McKann 1998; Velleman 2000; Searle 2001; Stoecker 2002. 
Events: Are all actions really events? Can all actions be localised in space and time? Is it really possible to say: "How long was I acting this time?" or "Wow, that was a short action!" Are acts of omissions, although actions, really events - and not the precise opposite of events? Are mental acts, although actions, really events? When does a decision (clearly an action) begin and when does it end? These questions can be summed up as the 'event problem'.

Causality: Closely linked to the event problem is the unsolved 'causality problem', a collective name for all the doubts and objections regarding primary reasons causing actions. Beliefs and desires are attitudes, but attitudes are not events, which is why the standard theory has to postulate the springing into existence of primary reasons for each action, a similarly bold hypothesis to Prichard's acts of will. Can such effective events really always be found 'close to' attitudes? Sometimes the desire for an action emerges at the same time as the action itself, sometimes not until afterwards. To what extent are primary reasons still causes of action if their descriptions only result from the overall action? Is accordingly the assumption of causality not restricted and the notion of a 'logical connection' between reasons and actions not reintroduced?

Intentions: Is the reductive view of intentions with regard to the beliefs/desires couplet really accurate? Do intentions not presuppose beliefs rather than encompass them? Are intentions not particular, referring to real actions, whereas primary reasons are general, are proattitudes towards a potential action? Do intentions (plans) not themselves create reasons rather than be reasons of their own? These and numerous other objections are evidence of the fact that the reductive concept of intentions within the standard model distorts everyday understanding and does no justice to the relative autonomy of intentions in our descriptions of actions. The overall result is an 'intentions problem'.

Rationality: How is it possible for primary reasons to rationalise? Is this an internal characteristic which requires no further conditions? Desires can explain why somebody has done something; how is it that they are also capable of justifying? Does explaining then coincide with justifying? Is it possible, within our conventional interpretation, that irrational primary reasons possess a rational aspect? Where is the difference when the agent is not capable of seeing his action in any positive light at all? It seems that it is possible to act without reasons, whether rationally or irrationally. Is a playful, spontaneous action 'without reason' an irrational action then, or, because it is without reason, even not an action at all? The 'rationality problem' of the standard model 
consists in eliminating the incoherence between explaining and justifying, and in finding evidence for a normative aspect within the primary reason. ${ }^{8}$

Normativity: Admittedly, the standard theory might have no intention of providing a comprehensive conception of practical reasons, instead merely proposing the general condition that primary reasons also have to possess a rational aspect. Even then, and bearing in mind the simultaneous proximity of explaining, it is still unclear how the primary reason can be linked to both explanations and justifications. Explanations require facts; justifications require more than facts. Reasons demand something, are commanding. How can beliefs and desires command? That is the 'normativity problem' of the standard theory.

Agent activity: Actions are only the actions of an agent if an agent executes them. That is why it is permitted to say that an action has an agent if someone with a primary reason for that action exists. But this condition is not sufficient: the agent must act from this primary reason. Causality alone (in this case agent causality) is not sufficient since unconscious desires (for example) would not constitute actions. The standard theory has a problem with agent activity, that is the active bringing about of an action by an agent. It does not pay this active aspect of actions enough attention.

How is this wealth of questions and problems surrounding action theory-partly new, partly old, partly aggravated - to be accounted for? One could possibly read it in the light of an interest in a gradually extended focus on actions, as especially being documented by the inclusion of the agent. Has the focus upon actions really shifted to acting agents and co-agents, compared with the earlier focus on single actions? One could also read the newer debate as documenting the breakdown of the standard theory and the turning back again, at least partly, to earlier positions. The intentionalist-rationalistic tradition prior to Davidson emphasised the subjective, deliberate and practical view of action, while neglecting causal explanations and running constant danger of itself creating inexplicable mental constructions. In contrast, the standard

8 These objections to the rationalising aspect of the standard theory become stronger if the theory is assumed to have an explicit conception of practical reasons. This is true for explicit normative variations such as M. Smith's (1987), but not for Davidson. The debate about external reasons referred to in the following (see section 5) only demonstrates the limitations of the standard theory; it does not refute its concept of practical reasons because it does not have one. 
theory emphasises the objective, causal and descriptive view of action, while neglecting singular causes of action and running the danger of ignoring the active, practical and rational side of acting. Due to these sustained tendencies within the standard theory, its ontological-causalistic onesidedness, this dichotomy has never been fully overcome.'

Davidson did not really succeed in linking the two strands of his proposed synthesis, the ontological-causal strand and the subjectivepractical strand. It is obviously not the case that a primary reason causes an action by rationalising it. Primary reasons are psychological states, and thus not events, and it is unreasonable that they could be located 'near to' events, just as the notion that a mug of beer could be located 'near to' my thirst is unreasonable. Not only do causal and psychological talk miss each other; it is also unclear why they should have to link up in the manner aimed at by Davidson. The psychological (and by extension social) demands made of our grasp of actions are all fairly familiar to us if we think about it, and without them we could not manage. The causal requirements may be familiar to some brain researchers and, especially, to metaphysical philosophers. In our everyday lives we might need to know how a desire or a belief has caused an action, but only in an argumentative-coherent manner and not in a physically causal one. We hardly ever say, "If only my primary reason of buying a cow at auction would cause me to drive to Haverford!", yet far more often "If only I weren't so unsure as to whether or not to drive to Haverford to buy a cow!", or something similar. In our everyday lives we do not have much use for 'purely' causal relationships, and it is our everyday lives in which actions take place.

If we really do not miss much by missing causality, the inevitable consequence is to describe the development of the standard theory as somewhat confused from the outset, insofar as it has been linked to a causal-ontological agenda. With reference to Davidson, it particularly becomes clear why he refused to apply his meaning holism to actions. If actions are also causal events, then they seem to resist generation through description: diseases are not easily healed, avalanches not easily stopped

9 Davidson was well aware of the deficit with regard to a 'practical' view of acting, as shown by the following comment in 'Intending': "The trouble is that the attitude of approval which the agent has ... has been left out. It cannot be put back in by making the premise 'The agent wants to improve the taste of the stew': we do not want a description of his desire, but an expression of it in a form in which he might use it to arrive at an action." (1980, 86) 
by describing them afresh. If actions are not causal events, as I believe, then they are just as mutually networked as sentences and words are. Meaning holism is necessarily also action holism. For both meanings and actions, it is true that they must obey practical and not ontological requirements, and they do.

For those who do not share this diagnosis, it may seem astonishing that recent debate, in the main part following on critically from the standard theory, has largely concentrated on the practical-normative aspects of actions, with the causalistic analysis of actions having shifted to the philosophy of the mind, an area which does less clearly answer practical interests. Three more recent sub-debates arise out of corresponding shady areas within the standard theory, namely the neglect of intentions, the one-sided concept of reasons and the omission of the agent. In the following I shall briefly outline the corresponding rehabilitation of three different classes of phenomena, concentrating in each case on one outstanding figure within these debates. Visible within these developments will be, as the minimum, the expansion of our view on actions by including the action-constitutive context. It should then, further, be easier to evaluate the extent to which a decidedly normative and non-causal concept of action is borne out by these developments.

\section{Intentions and Commitments}

The intentions problem within the standard model is conspicuous and has been attacked in many comments. The problem partly springs up quite simply from the standard model's reductive treatment of intentions and partly from the non-coincidence of intentions and causality, something becoming apparent in the 'deviant causal relationships'. ${ }^{10}$ Interpreting intentions reductively means equating them to the existence of beliefs and desires; in so doing, various functions fulfilled by intentions are disregarded. Bratman's 'planning theory of intention' is the most systematic and detailed attempt to develop these functions in a non-

10 On intentionality see esp. Thalberg 1985, 20-24; Stoutland 1985; Bratman 1984; 1985; 1987; Wilson 1980; 1985; McKann 1991; 1998. Also note Davidson: "At one time (about twenty-five years ago, when I wrote 'Actions, Reasons and Causes') I thought there were no such states as intending; there were just intentional actions. This was, I now believe, an error." (Davidson 1987, 106) The problem of deviant causal relationships is one of the motors firing the agency debate. See section 6 below. 
reductive form. The reductive treatment of intentions seems to be descriptively inappropriate, it is true, but it does have, as we saw earlier on, good reasons by reacting to the difficulties surrounding the voluntaristic-rationalistic tradition. Is the planning theory capable of avoiding these difficulties?

Davidson himself toned down his initial (1963) aversion to "mysterious acts of will" $(1980,83)$ by the time he wrote his article 'Intending' (1978), in which he proposed a less reductive analysis of intentions, giving intentions a certain autonomy on the basis of the elements inherent in the standard model. In a first step proceeding from acts of 'pure' intending, i.e. those not linked to subsequent action, he explains intentions along the lines of a practical syllogism; in a second step, he explains them as 'all out' judgments of what is desirable (1980, essay 5). One difficulty in linking a particular individual action not only to primary reasons, but also now to an evaluation as desirable, arises from the particular reference to actions. Desires and what is desirable frequently refer to actions in a special regard, not to special actions. With the conditions of an all out judgment, Davidson wants to guarantee that this judgment refers to a particular, real action. Assuming that were true, how is a similar analysis of intentions meant to refer to future actions, as all out judgments can hardly address particular actions taking place in the future? Reversing the analysis and interpreting (in my opinion more plausibly) the assignation of 'desirable' as general in every case, then the opposite question arises of how one can intend a particular, real and now executable action under this general term.

Bratman's planning theory of intention comes into play with regard to the differences between desires and intentions, differences which cannot really be bridged using judgments of what is desirable. For decision-makers facing a Buridan's ass situation, in which competing alternatives are desired equally and are equally desirable, an intention to seize one alternative is obviously possible even though the desires cancel each other out (Bratman 1985, 219). For rational agents, intentions are guided by an agglomeration principle, whereas desires are not (220). The problems in Davidson's theory surrounding a particular or general reference to actions mask an additional fundamental difficulty in how to cope with intentions directed at future actions. Davidson tries to comprehend intentions directed at future actions as extended versions of intentions directed at present actions, but he fails because some intentions to act in the future will not be desirable due to unenvisaged circumstances impeding those actions. Bratman wishes, on the one hand, to agree with 
Davidson that beliefs/desires are essential components of rational action, but, on the other, wishes to grasp the role of intentions more decidedly by way of those subfunctions of acting which render an agent a rational agent. The planning theory is a normative reconstruction of intentions by means of their rational function within individual and cooperative plans of action.

In a reversal of Davidson's attempt to reduce future-directed intentions to present-directed ones, the planning theory assumes that present-directed intentions can only be explained against a background of future-directed intentions (Bratman 1987, 4). Unlike intentions directed at typical actions in the present, future-directed intentions raise considerable difficulties. How are intentions which are shaped today for an action taking place tomorrow linked with tomorrow's action? Do they control that action with a ghostly hand? If they are irrevocable, does that not render them irrational due to their inflexibility regarding possible interim events? Such intentions would then indeed be irrational. These ontological and rational difficulties with future-related intentions miraculously dissolve if they are understood as commitments within plans of action, which have a normative character due to the mere fact of their integration in rational conditions, such as consistency or the coherence of means and ends.

The Copernican point, as it were, from which intentions are comprehended as parts of plans, is marked by the term commitment, for only by means of this explicitly normative concept of binding oneself do the various normative functions of intentions within the open network of plans become accessible. ${ }^{11}$ Intentions involve commitments, which can be described in terms of their various practical functions. A commitment is thus expressed in a concomitant controlling of action, as well as in a sensitivity to reasons. The commitment involved in future-directed intentions ensures that the aim of an action remains firm into the future, as well as that it is rationally adapted to the actual requirements only revealed with time. Via these two elementary functions the actions of an

11 The introduction of this concept is Copernican in that it permits a radical renunciation of Davidson's individualistic perspective, albeit without, similarly with Kant himself, making clear reference to the social community in a normative respect. See Brandom's illuminating comments on the difference between Kant and Hegel on this point: Brandom 2002, chap. 7, esp. 216. Bratman does emphasise the social significance of commitment but ignores their normative-constitutive role. 
individual agent can be anticipated by others, which in turn facilitates cooperative action within the collective (Bratman 1987, chap. 2).

It seems to be descriptively plausible to say that intentions fulfil such practical functions, but if they additionally become rationally effective, if the rational structure of acting is shifted to the formation and control of intentions, what significance do beliefs/desires then retain? The planning theory differentiates between internal and external perspectives with regard to an action. The internal perspective is the one which is characterised by the intentions already formed and the decisions taken by the agent. These commitments are not only necessary in order to continue pursuing plans of action in a controlled and rational manner into the future; they are also advantageously unburdening for boundedly rational agents, 'boundedly' in the sense of $\mathrm{H}$. Simon's concept of bounded rationality. The external perspective, on the other hand, is the perspective free from the agent commitments, partly stemming from the agent's beliefs and desires, partly also revising them. The external perspective is accessible to the agent himself, but also of course to potential observers. Both perspectives additionally possess an ideal dimension and therefore contain internal and external norms (109). To summarise thus far, intentions are psychological states capable of forming commitments which are rationally connected to plans of action structured by internal and external norms.

As innovative as Bratman's normativistic reconstruction of intentions is in its various ways, some important points within it remain unexplained, partly as a result of its ongoing attachment to basic ideas of the standard theory. Firstly, the importance of commitment, as well as the connected plans and norms for intentions as mental acts remain unclear, and the same goes, secondly, for the relative weights of the internal and external perspectives. Both points are important for any evaluation of just how 'Copernican' Bratman's proposal is. Intentions and plans are psychological states (29) which contain commitments. Commitments are reason-centered and, as we have seen, contain internal and external norms. Normativity of this kind cannot be fully dissolved into psychological states. According to Bratman, plans are hierarchically structured (29). Yet is a hierarchical structure itself a psychological state? Intentions contain commitments, but are not commitments themselves. But what, then, are intentions independently of commitment? Like Davidson, Bratman attempts to avoid the idea of a "ghostly influence on the future" (110), but leaves open the dependency of psychological states upon normative demands. Comments like "plans are ... intentions writ 
large" (29) may not be meant literally, but are still leaning heavily on the mental fundamentalism of the standard theory.

Bratman wishes to hold on to the beliefs/desires rationality norm of the standard model, chiefly discussing the rational dependency of intentions by referring to a requirement that intentions be revised in the light of a conflict between the intentions and the beliefs/desires of one and the same agent. All principles of internal consistency, the coherence between means and ends, the external norms, are seen as expression of the rationality of desire $(43,109)$. The planning theory is thus subject to all the objections which have amassed to the rationality of beliefs/desires and which will be addressed below. The normative conflict between the internal and external perspectives requires an answer which cannot be provided using the standard view of practical rationality. The external perspective is not simply just a potentially better awareness of empirical facts, but a comprehensive social view of the norms governing perceptions, desires and knowledge, being reproduced by the agent's ongoing work of shaping his assumptions in response to social challenges. "Reason-responsiveness" or "discursivity" would therefore pinpoint the function of the external standpoint better than the enlistment of corrective knowledge regarding desires/facts.

If we interpret Bratman's planning theory a little more radically than he intended, however, it provides an impressive argument for how constituent components of individual actions, like intentions, cannot be comprehended without an open horizon full of agents all acting for reasons and all coordinating their actions. Without reliable commitment cooperation is impossible (Bratman 1999, chap. 5-8), but without external norms reliable commitment is equally impossible. Various social contexts challenge the intentional and thus firmly future-directed actions of an individual agent. But social contexts do not only represent challenges (Bratman 1999, chap. 1), facilitating the rational revision of intentions and plans; they are changing scenes for individual actions and a changing stage at the same time. 


\section{Practical Reasons: Internal or External?}

According to the standard theory, beliefs/desires are primary reasons which at least precede all other reasons. ${ }^{12}$ In this context "reason" can have more than one meaning:

- "cause"/“motive"/“motivating reason"/“explanatory reason", or

- "justification"/“justifying reason"/"normative reason"

This bifurcation is meant to distinguish a list of (relatively) descriptive terms from a list of (relatively) normative terms. In addition, the differences between the individual terms are complex and cause for some controversy within the current debate. Due to the ambiguity of most of these terms, the type of action and rationality theory one subscribes to (including the context of these theories themselves) decides the mutual relationships in which one views these terms. At the centre of these differences reside divergent views on what it means to act 'rationally' or 'morally', what the 'normative' resources for these actions are, and in which normative framework actions therefore have to be perceived.

Let us try to bring some kind of order to these various terms (see also Dancy 2000, chap. 1), starting with reasons as 'causes'. In view of the thin relevance causality has within the explanation of ordinary actions, we can in this context disregard the idea of reasons for action being causes. ${ }^{13}$ Explanations of actions refer explicitly to motives (and thus at best to 'causal terms'), not to causes and laws.

Reasons as 'motives' and reasons as 'motivating reasons'. The difference seems to be that talk of a mere motive has no normative claim, whereas talk of a motivating reason has at least a weak normative claim. "His motive was jealousy" and "his motivating reason was jealousy" differ in that the former is closer to "his motive was insomnia" and the latter closer to "his motive was the belief that he was being betrayed". Talk of a reason thus oscillates between a reason which from the point of view of the agent cannot be rationalised and a rational reason, whereby the concept of 'rational reason' can in turn be interpreted more or less broadly.

12 Some authors, e.g. Smith 1987, believe them to be the only kind of reason.

13 See Thalberg 1985, 16-20; Stoutland 1986. Davidson might not have maintained that the primary reason in explicit form has to be the cause of an action (Davidson 1987), and yet he, too, advocates its causal role. Similarly, Hornsby finds it strange "that the rational explanation of action mentions causes but is not itself causal explanation" (Hornsby 1993, 135). 
Reasons as 'explanatory reasons'. The explanation of why an agent has done something can be, but does not have to be due to a motive, for example in an omission to act, still perceived as an action even though it results from negligence. Disregarding the vague category of omissions (are they actions or not?), explanation can result from motives or motivating reasons and is subject to the abovementioned differing degree of consciousness or rationality.

A resumé about the first group of terms would be: reasons in the sense of 'motives' or 'motivating reasons' are necessary elements in the description of actions. Actions cannot be without motive, and, depending on the meaning of the term, can hardly be without a motivating reason either.

Reasons as 'justifications', 'justifying reasons' or 'normative reasons': The difference between 'justifications' and 'justifying reasons' is minimal. The former are usually given afterwards; the latter are usually consciously linked to current activity. More important is the difference between justifications and normative reasons. Justifications require an agent whose justification they are, whereas normative reasons do not. The two can accordingly diverge. $A$ is justified in taking the book away because he believes it to be his. But this may not have been a good reason to take the book away if the book actually belonged to $B$. Justifications are reasons which are presumed to be good from the standpoint of the agent; normative reasons are reasons which are not good from anybody's particular standpoint, but are the best reasons available. The exact connection between the two raises considerable problems, as we shall see in a moment.

Talk of 'normative reasons' certainly leads us into problematic terrain because precisely this term is used and reconstructed differently in different theories of rationality. Whereas the Humean tradition traces back any normativity of reasons to desires under suitable conditions, the realistic and intuitionistic opponents of this tradition (Platonists, Reid, Kant, Moore, Korsgaard, Dancy) view reasons as not subjectively reducible. ${ }^{14}$ Whether one believes normative reasons to exist or not, and

14 Wittgensteinians, who deplore fits of dizziness confronted with any step towards abstraction, already struggle with talk of 'normative' and 'normativity'. "Normative" and "normativity" are certainly predicates with more than one meaning and unite the characteristic of being prescriptive with that of being objective. The problem with normativity lies essentially in this combination which is not immediately reconcilable. How can something which is supposed to be objective motivate, and how is a subjective motive supposed to be objective? 
how one reconstructs them are also closely linked to how one sees the relation between the descriptive and the normative versions of reasons (the first and second types in the list above). In any case the relation has to be explained via an identity bridging the two types of reason. Motivating reasons are reasons which enable an action to appear positive and therefore suggest to an agent, command him in fact, to execute that action.

Advocates of the standard theory choose to relate motivating and normative reasons as follows:

Corresponding to the belief and attitude of a primary reason for an action, we can always construct (with a little ingenuity) the premises of a syllogism from which it follows that the action has some (as Anscombe calls it) 'desirability characteristic'. Thus there is a certain irreducible-though somewhat anaemic - sense in which every rationalization justifies: from the agent's point of view there was, when he acted, something to be said for the action. (Davidson 1980, 9)

To serve as reasons for an action, beliefs and desires need not be reasonable, but a normative element nevertheless enters, since the action must be reasonable in the light of the beliefs and desires .... (Davidson 1980, 84)

What is special about the (action) explanation is that Eve's desire and belief explain her action in part because they provide Eve with a reason so to act. (Bratman 1987, 14)

To sum up these remarks on reasons so far: firstly, "reasons" in connection with actions is a term with many meanings and an especially descriptively and normatively ambiguous and dithering one. Secondly, "reasons" can refer to motives for action which are rational to differing degrees, i.e. deemed good and thus executed by agents to differing degrees. The assumption that an agent always presumes his actions to be good, otherwise he could never be asked why he does what he does, is not implausible (albeit highly controversial). ${ }^{15}$ Thirdly, motivating reasons are, by virtue of the use of the term "reasons", to be comprehended as

Disregarding these problems, talk of 'normative' reasons seems to be essential if one wishes to say why a reason prescribes something or is a prescriptive reason. To reject normative reasons is also a rejection of prescription or practical necessity.

15 It is possible to argue against this assumption, especially with reference to examples of arational acting (Hursthouse 1991). For other examples and the discussion of irrational action situations, see Anwander 2002. Opposing Raz 1999, Anwander believes that an action does not have to include being deemed good in order to be understandable. In my opinion, this debate should be read as centering on the framework or the system of understanding action, not on single actions. 
justifying reasons. Fourthly, anyone employing justifying reasons positions himself, we can assume, within the 'space' of normative reasons. All actions are then indirectly tied to normative reasons, even if they are not necessarily correspondingly motivated.

I believe that one should better not read Davidson and Bratman in the sense that they would oppose extended embedding and back-reference to normative reasons, thus erecting a barrier between action theory and rationality theory. Even though he did not observe the difference between justifying and normative reasons, Davidson has, with his demand that explanations for action should be "rationalisations" (1980, 3), embedded actions within the space of rational action and thus also that of normative-rational action. Davidson did not, surely, advocate an explicit normativity thesis, according to which actions are necessarily embedded within the space of normative reasons, and it is doubtful whether he wished to advocate one. According to the normativity thesis not all actions are necessarily justified as such, justified at all or motivated by reasons, but all actions are per se subject to the ideal of being justifiable or of being related to normative reasons. Without such an assumption, there would be no connection between the areas of motivated and right action.

One consequence of the normativity thesis is that the shift of interest away from the issue of which reasons must be necessary components of an action towards what constitutes practical and especially moral reasons represents not a transition to another topic, but makes for a part of an extended analysis of actions, analoguous to the transition from intentions to plans in Bratman's planning theory. If reasons for action depend on 'good' reasons, then one cannot understand actions without understanding the foundations underlying these good reasons; action theory cannot do without normative foundations, which are usually seen as being located firmly within metaethics and ethics. The same result springs from the two most important questions surrounding the rationality of practical reasons: in addition to the obvious question of what makes these reasons normative, the second crucial question of how normative reasons can motivate would be incomprehensible if it were not reasons for actions which were being discussed.

Before I address these questions and the normativity thesis in more detail, I should like to draw attention to an additional integrative hunch definitively represented by the standard model and partly in competition with the normativity thesis. Advocates of the standard model, especially those who are interested in the causal relationship between reasons for action and action, frequently impute a naturalist claim, according to 
which a close (reductive, corresponding or other) relationship exists between brain states and propositional attitudes. Naturalistic assumptions or strategies can be articulated and pursued in different ways, but overall they provide strong motives for viewing reasons for action as subjective states, in contrast to normative-social relationships (see Stoutland 1998, $48 \mathrm{f}$.). Following a reductive conception of reasons, it is possible to reconstruct beliefs and desires as symbolic representations which are not actually characteristics of persons, but ontological states in their own right. Opinions differ as to whether the naturalist claim is necessarily linked to the standard model or not. Davidson's pronounced intention of comprehending reasons as causes certainly suggests naturalistic tendencies, but this does not necessarily have to be linked to a full naturalism. ${ }^{16}$ Just how Davidson's original aim of uniting reasons and causes is supposed to be achieved, remains an open question and cannot be pursued any further here. In line with probably the majority of those involved in the current debate on reasons (including Davidson himself), I am of the opinion that normativity takes priority over reduction attempts. In the words of F. Stoutland:

... nothing from the physical realm can determine what is a real reason for action or make it true that an agent acted for this reason rather than that. (1998, 53; more detailed Dancy 2000, 163)

Let us return to the normativity thesis and the embedding of motives in normative reasons. In Davidson's works the difficulty surrounding the precise depicting of reasons for action-disregarding the controversial problem of the causality relation-is not all that ponderous because no explicit difference is made between justifying and normative reasons, and the paradoxical bifurcation of practical reasons being normative and motivating remains hidden. The gulf between motivation and objectivity becomes more visible if a clearer distinction is made between motivation and objectivity, as suggested by Williams' famous article (1981). According to Williams' terminology, a restaurant guest desiring alcohol has an 'internal' (subjective-justifying) reason to drink a glass allegedly containing gin. In addition, there can be an 'external' (objectivenormative) reason not to drink the alleged gin: the fact that the glass actually contains petrol. What is the relationship between subjective-

16 The opposite diagnosis referring to Davidson in his early work is defended by Stoutland 1998. In his opinion, Davidson later distanced himself from the standard model in this naturalistic sense. See Stoutland 1999. 
justifying and objective-normative reasons, and what, in turn, is the connection to a motivating reason? If not to drink from the glass is a good reason, even though I am unaware of it, what significance does it then have for me that reasons are connected to my psychological attitudes, as postulated by the standard theory?

The problem can similarly be formulated using "explaining" and "justifying". If the primary reason were simultaneously to explain and to justify, the normativity thesis would be met. Objections? The standard theory was simply not articulated explicitly enough in order to render visible the extent to which it is capable of fulfilling the demands made of practical reasons. One criticism is therefore that the normative profile of the standard theory needs to be developed in more detail; another criticism addresses the resulting desire-based conception of reasons. Criticism of the first type arises from questions such as: Is a primary reason the entire normative reason or merely one of its constituent parts, the belief or the desire, possibly in each case in a certain dependency on the other part? Can a psychological state, such as a belief or a desire, be a normative reason at all, in contrast that is to the object of a belief or a desire?

The standard model is usually vague about whether the reason is to be found in the belief and/or the desire. ${ }^{17}$ Firstly, it is vague regarding the way in which expansive talk of 'primary reasons' is certainly helpful in order to be able to reconstruct varying examples which include by name not desires, but all manner of emotional attitudes, in other words the way in which a pro-attitude can always be proven on the basis of these examples; it also becomes unclear, however, what else is claimed alongside the primary reason. J. Searle's example, for instance, in which one would have no reason to pay for a beer one has ordered if one felt no desire to pay for it $(2001,27)$, is hardly an appropriate illustration of the model. But does the beer drinker really have a belief that sanctions are to be expected if he refuses to pay, and does he really have a desire to avoid those sanctions? How do we proceed if someone does not explicitly have the corresponding beliefs/desires?

Secondly, there is a conflict between beliefs/desires as psychological states and as normative attitudes. One still has normative attitudes even when they are not psychological states, and wanting to reduce them to psychological states is problematic. In this point the standard model is

17 "The main idea is that the agent's desires and beliefs at a certain time provide her with reasons for acting in various ways at that time." (Bratman 1987, 15) 
generous, with its terminology covering both, thereby posing a challenge to the current debate on practical reasons, in which reasons as psychological states are certainly no longer primary reasons.

Put another way, one could also say that the standard model is vague in two respects and has correspondingly given rise to two types of criticism: first, it stimulated reservation that desires or other psychological states could be the only or the dominant source of normativity; second, it gave way to doubts that subjective psychological states could be capable of carrying truth-claims. The first sort of criticism follows the tradition of hedonistic and related empiristic value theories; the second sort of criticism is of an epistemological and ontological nature, namely interested in the correlation between belief, reality and truth.

The first concern corresponds to a traditional scepticism as to whether desires can be normative or bearers of truth-claims, whereas the second concern springs from various sources. In its constructive version it consists in an attempt to reconstruct the link between the different types of reason, an attempt to link the subjective and the objective. These constructive attempts also try to counter a doubt about whether the standard model can conceive of acting as real acting, acting within a real world. Criticism of the first kind could be called the naturalist-criticism ${ }^{18}$, the sceptical second kind the idealist-criticism. In the following I shall skip the rather well-known naturalist problems within ethics and will concentrate instead on the idealism/realism puzzle. ${ }^{19}$

The idealist-criticism is targeted at desires, beliefs and possible combinations of these. It is not directed at beliefs and desires per se or at beliefs and desires in a certain mutual relationship, but at beliefs and desires as psychological states. The key point of criticism is: normative reasons for an action must prove this action to be good or correct, and

18 In the wake of G.E. Moore's use of "naturalism" in ethics, which is not identical to the previous, much broader concept of naturalism.

19 Dancy criticises desires as the basis for reasons with the charge-familiar from the Kantian tradition-that desires are contingent and ill-founded. Because desires themselves require reasons, they can be jumped over in justifications (Dancy 2001, chap. 2). Rebukes like these are certainly exaggerated and would render theoretical and practical reasons mutually indistinguishable (see Darwall 2003). It would also be impossible to explain why there are (correctively effective) reasons for desires if desires themselves play no role at all. Scanlon's 'buck-passing account' (1998) does far more justice to this problem of coherence and shows that flouting desires need not lead to a realistic conception of reasons as Dancy's. 
psychological states, with very few exceptions, are not capable of doing this (Dancy 2000, 102-107; Bittner 2001, chap. 7; Stoutland 2001). ${ }^{20}$ Since this objection refers to psychological states in general, it is equally valid for beliefs and desires, and indeed is meant to be so. A desire is not a normative reason because it is only as good as what it is directed towards; a belief is only as correct as that which is believed. Beliefs and desires are capable of subjectively justifying only if they can prove correct, and this can only be done by referring to the factive qualities of their objects.

This criticism is partly based on examples from our everyday thinking, but overall it is just as plausible as the suggested factive conception of normative reasons is tenable. Such reasons are usually states of affairs which are independent of an agent, and very occasionally states of affairs identical with psychological states of the agent. ${ }^{21}$ In some cases an agent believes he has to react to his psychological states, usually dispositions, and if this assumption proves to be correct because not taking his disposition into account would mean advantages or disadvantages relevant to his situation, he then has a good reason. An agent prone to vertigo, for example, has a good reason not to approach the edge of a cliff if he is afraid of losing control and if he actually would lose control. Typically, however, an agent acts from assumptions about others and about the world surrounding him; the typical case is not formed by selfperception of one's own dispositions, but by perception of the conditions governing the surrounding world. In contrast to this the standard theory promotes exceptional cases to typical cases by raising psychological states, at best suited to justifying, to the status of general normative reasons.

Viewing normative reasons as states of affairs represents, in more than one way, the precise opposite of the standard model's notion of normative reasons. This is also demonstrated by three consequences which Dancy, in particular, is prepared to face. First, the strongest possible answer to the question of how motivating and normative reasons are supposed to be linked is a claim to their being identical or nearly identical, reasons are motivating due to the qualities of their states of affairs (2000, esp. chap. 5.3; also Bittner 2001, $\$ \$ 236-242$ ). From a diametrically

20 A number of authors, including these three, put forward the idealist-criticism and an alternative 'factive' concept of reasons at more or less the same time. Below I shall concentrate particularly on Dancy 2000 because his theory is both the most comprehensive and the most radical. The differences between Dancy, Bittner and Stoutland are slight, however, and will be mentioned in passing.

21 'States of affairs' are understood here in the sense of actual states, not in the sense of logically possible facts, following the Tractatus convention. 
opposed standpoint, Dancy thus once again approaches the standard theoretical idea that reasons and motives coincide (see Dancy 1995). Second, due to the now ontologically reversed point of view, explanations for an action are not causal explanations for that action, stemming from psychological states of the agent, but normative explanations. The theory thus circumnavigates the problem of action causality (2000, $84 \mathrm{f} ., 163$; Bittner 2001, chap. 5). Third, normative reasons are not (as in the standard model) opposed to empirical reasons; external states of affairs are normative states of affairs: "(R)eality is practical." (2000, 137) (In contrast, Bittner is of the opinion that reasons are always only empirical reasons/states of affairs and normativity per se is something which is extremely dubious $(2001,69)$.)

Can this normative realism of reasons really be upheld in the light of such amazing extensions? Once again, Dancy in particular has clearly identified and attempted to deal with two key difficulties. Reasons as states of affairs somehow need to be linked to the agent as his reasons for his actions: how else than through the psychological states of the agent? Do they not need to be taken into account once more as part of the reasons? And what about the erring agent? In the case of an erring agent motivating and explanatory reasons cannot be states of affairs as, due to the error, there is no such state. Is this not evidence of the secondary role of states of affairs and the primary role of psychological states?

Dancy has provided inventive answers to both problems, their plausibility remaining controversial, including in parts of this book, and raising reservations as to whether these answers have not caused the difference between the factive reason-conception and the standard model to become considerably narrower. According to Dancy, the psychological states of the agent are "facilitating conditions" or "appositional" conditions of the realistic explanation, but not its component (2000, 126-130). An agent must be in the correct frame of mind for a state of affairs to be, for him, a reason, without the frame of mind itself being part of the reason-with the exception of rare or pathological self-related cases (124). In this way, states of affairs giving rise to reasons are integrated in the agent's perspective of consciousness; reasons for actions are always accompanied by a knowledge of the reasons without them becoming psychological reasons (Bittner 2001, $\$ \$ 191-193$ ).

How to deal with the erring agent who thinks he has a reason but in reality does not? One possibility would be to resort to propositions or mental entities which can step in for what is maintained but is not really the case. In the light of the idealist-criticism this move would be a 
regression and would more or less amount to a silent acknowledgment of the standard theory. ${ }^{22}$ Thus the only things remaining are references to parts of factive circumstances. This is the solution Dancy favours. He chooses throughout to adhere to the notion that a state of affairs explains normatively and motivationally why an agent finds an action good; in the case of an erring agent, this state of affairs is a non-given state of affairs. A state of affairs which is merely not given can be eliminated because it would beg the question in what way (in psychological states?) it is not given. Dancy therefore postulates, if not exactly in these words, nonexistent states of affairs as states of affairs. This seems clearly a reductio ad absurdum, which Dancy chooses to ignore with ambiguous, no longer realistic comments. ${ }^{23}$

Bittner opts for a different solution. If an agent thinks he is acting for a reason which, so it transpires, does not actually exist (a state of affairs which is not given), then he acts without reason. The agent acts from a psychological state of belief, which does not prove, however, that this state is his reason $(2001, \$ \$ 199-212)$. A nasty aftermath of this version of events seems to me to lie in the following. Either one chooses an artificial way of talking according to which this agent acts 'for' a reason, if not 'out of' a reason, then one leaves open how both these kinds of acting for reasons are normatively linked. In not being explicit regarding the connection one refuses to try to achieve coherence between the subjective and the objective side. Alternatively one could say that the agent acts for no reason at all, thereby neglecting the fact that he thinks he has a reason. Bittner says that the erring agent acts for no reason at all, whereas we would normally say he acts for a mistaken reason. Someone acting for no reason at all is, with the exception of a specific class of spontaneous or extravagant actions, acting irrationally, whereas the erring agent is acting as rationally as one could possibly imagine. Neglecting this difference does not seem to be a good thing either, so the factive reason theorist still has to give an answer to the case of the erring agent. Several authors in the present volume elaborate on this puzzle.

22 Dancy discusses a theory which is slightly different from the standard theory with equal criticism $(2000,121-126)$.

23 "... there is no metaphysical problem about the nature of that which is believed when the belief is false, because of the intentionality of belief. A belief can have, as it were, a non-obtaining content without having no content at all." (147) "Perhaps all that needs to be said ... is that the content of a belief, what is believed, is something that either is the case or not." (148)-In both cases the content is dependent on the belief, not vice versa! 
If Dancy's and Bittner's radical attempts tangle things up, some conventional differentiations once again need to be observed, for example the difference between explaining and justifying. J. Wallace has emphasised that the focus of explaining is on the actual state of the agent, whereas that of justifying is on the truth of a state of affairs, meaning that it cannot be correct to say that the two types of reason are almost identical (Wallace 2003). It seems to me that the appropriate relationship between explaining and justifying is to be found at the core of the conflict between internal and external reasons. Dancy connects the two because he sees human motivation as being essentially characterised by the rationality of believing something to be good, the latter in turn being founded in real states of affairs (Dancy 1995). Instead of directly identifying both by means of individual states of affairs, perhaps it would be better to bring them together at a more background level, for example through 'rules', 'practices' or 'habits'.

In this point Stoutland's sketchy, Wittgenstein-inspired comments (1998; 2001) seem to be more promising than Dancy's (and Bittner's) adherence to immediate states of affairs. On the one hand, rules and regularities solve the task at hand, i.e. make it transparent why an agent acts, from his own point of view as well as that of others, and they are also normatively easier to understand than states of affairs beyond actions ("the sun goes down"). On the other hand, they have the background character to give particular justifications and explanations the necessary scope. This may be narrower or broader, depending on the type of action. Stoutland's (2001) example of stopping at a stop sign, a practice within a strictly regulated system, is surely not representative of most actions. But indicating that there must be a common system of rules governing our reasons to act does point us in the right direction for tackling the difficulties in Dancy's theory of reasons.

If these observations are right, then the problem of connecting internal and external reasons, explanatory and normative reasons, the first-person and third-person view of actions, the different standpoints (Wallace 2003, 431) arising from the confrontation between more subjective and more objective action theories, should be transformed into more fruitful questions: Out of which common social system of rules can individual agents meet each other in different types of reason? How do the stipulated rules permit an explanation of individual actions even if they are based on false assumptions or a failure to adhere to those rules? The standard model and the factive reasons-position are theories which have been driven to opposite extremes, and this opposition can only be 
overcome by using a level which is common and necessary to all the elements involved, in order to create the desired connection between explaining, justifying and truth. Similarly to the case surrounding Bratman's planning theory, the debate about reasons therefore leads into an extended view of actions, in order to understand actions.

\section{Actions and Agency}

Some, like Frankfurt, choose to formulate the central question of action theory by explicating the contrast between what an agent does and what merely happens to him; others simply concentrate on the difference between individual action and a bodily movement. Agents are already implied with the mere mention of actions, or so one could think. This assumption might have put the minds of standard theory advocates at rest about the fact that when they begin their analysis of action with individual actions they construct no actions, at least in principle, without agents - similarly to the way that linguists see no fundamental problem in directing their theory at sentences and not at speakers, silently assuming that sentences are always the products of speakers.

Two key motives behind the standard theory were, however, first, to avoid the regress within Prichardian volitions and, second, to allow reasons and causes to become compatible. These two motives force the standard theory to exclude the agent of an action to a greater degree than is apparent at first sight. Unlike acts of will, agents can possess beliefs and desires independently of their special role as agents; dispositions of the agent can lead him to act without recognising these acts himself as his own. As a result of its programmatic motives, the standard model objectifies action in a way which renders it difficult to recognise the role of the agent within the actions analysed. To use a term which in the last few years has received increasing attention: the standard model has a problem with 'agency', a central characteristic of the agent and the action.

The term "agency" is, like all general terms used in action theory, an artificial, philosophical expression and accordingly unclear. At the heart of the term is an intuition that the action cannot be separated from the agent, or that it shares something with the agent whose action it is: an element of the activity, the perspectivity of the agent or the execution from his point of view. If - taking the terms "agent" and "action" as given- "agency" is a relational term, then it comprises both the aspect of agency, an activity of the agent, and the 'actorial' characteristics of the 
action, characteristics which cannot be described without reference to the relevant agent. Because of its relational character, both the agent side and the action side of agency can be emphasised, both agents and actions can be 'actorially illuminated'. Given this potential purely verbal emphasis becomes problematic when, as in Davidson's (1970) discussion of action activity, the agent is not only no longer included, but is also no longer conceivable (e.g. Velleman 1992; Hornsby 2004a). The difficulty the standard theory displays is that it not only does not provide a satisfactory concept of action activity, but—ringing a little crazy—systematically excludes any active involvement of an agent.

What deficits within the standard theory spark this accusation? Firstly, the inappropriate concept of a causal explanation of actions. By turning the everyday explanation of an action into a causal relationship between events due to beliefs/desires, it abstracts from the teleological sense of that action. One would not expect the explanation of an action to consist in information as to why a mental event brings forth a bodily movement. By abstracting from the activity, a causal relationship does not explain. Secondly, and somewhat more special, the standard theory cannot distinguish genuine actions from determined behaviour or from actions due to unconscious beliefs and desires. Explanations based solely on psychological states lack the actorial authority which typical actions have to possess. This objection is independent of causalistic problems and is orientated towards the everyday demands made upon explanations of action. Thirdly, it is hard to see how the standard theory wishes to solve the normativity problem if it does not permit any critical reflection regarding motives for action, i.e. the beliefs/desires pair. A complementing of the premises surrounding critical reflection methods to date is barely conceivable if the agent is not taken into account in his relationship to his beliefs, his desires and his intended action. ${ }^{24}$

These three difficulties can be supplemented with a fourth one which has been recognised for some time, the difficulty confronting the standard theory with regard to actions spinning out of control. More clearly than any of the other difficulties, 'deviant causal relationships' question the two basic elements-the belief/desire pair and the causal relationship. Since Davidson's first indications $(1980,79)$ it has been

24 See Hornsby 2004a, 8, for the first deficit and Bratman 2000 for the remaining two. The first objection does not fully apply to Davidson, according to whom explanations of actions are not direct or explicitly causal explanations. See Davidson 1987; Stoutland 1999. 
clear that a suitable psychological state of an agent can, in the course of an action running out of control, cause an action result which in content equals that which was desired, thus rendering the conditions of the standard theory fulfilled, even though it amounts to either no action or a failed action. ${ }^{25}$

What these four problems in the standard theory have in common is that they all arise from an activity-relevant, as well as actorially underdefined description of the premises of the action. However, they are all inadequate at different levels of describing and explaining actions, so that different deficits and types of action activity are addressed. Although various action theorists (Frankfurt, Velleman, Bratman) have begun to deliver more and more detailed analyses of the 'comprehensive' agent, it remains controversial why and to what extent they are forced to do so from the narrow interest of the analysis of individual actions. The explanation of actions compels the inclusion of action activity-but how comprehensive must the concept of action activity be, leading to a concept of agency and a comprehensive theory of the agent, including his rational, biographical and social characteristics? To what extent must a theory of action lead into, or be developed from, a theory of the agent?

The discussion becomes slightly clearer if, in the question of how broadly the concept of action activity has to be construed, one differentiates between 'minimalists' and 'maximalists'. Minimalists (like Hornsby) believe the inclusion of agents to be necessary in the analysis of individual actions, but without aspiring to a normative construction of agents. Maximalists (like Frankfurt, Velleman, Bratman) believe that explanations of actions require per se inclusion of the agent and his role within the 'rational aetiology' of the action. The maximalists have a plausible reason for this, it seems. If one demands of an action that it has to be rational in a certain way in order to be an action-even if "rational" is only meant in the sense of a coherence of action and belief/desirethen the concept of agent which is to be included, itself has to be a normative or rational concept. In addition, as Hornsby suggests (2004a), a further motive of the maximalists is presumably their adherence to event causality, so that their proposals of action activity and agency can be

25 Famous examples of this are the climber who unintentionally allows his partner to slip, the nephew who by chance runs over the uncle he is to inherit, the bank robber who signalises through his nervosity the begin of a break-in, etc. Discussions are included in: Frankfurt 1978; Peacocke 1979; Bishop 1989; McCann 1998, chap. 4; Velleman 1992; 2000, Introduction. 
meant as an extended version of the standard theory, in which the explanans events now consist in more complex (normatively mediated) psychological states of the agent. ${ }^{26}$

In this controversial situation it could be helpful to separate between the philosophical-ontological perspective and the everyday demands made upon explanations of actions. Two interesting questions are then, first, whether the adherence to event causality is reasonable within the extended concept of action activity, and second, why, independently of that, the concept of the agent actually has to be normative, and to what extent. For the first question the manner in which one assesses the problem of deviant causal relationships is enlightening. Even 'causalists', or so it appears to me, can no longer stand by the view that causal relationships, if they exist, are informative for the type and existence of an action, in the conventional sense of action, so that (comparable to determinism seen compatibilistically) causal relationships can be conceded, but are eliminated from the analysis of actions as sources of information.

Davidson's answer to deviant causal relationships was that it is crucial to make a distinction between a 'correct' causal relationship and irregular ones, in order thus to contain actions causally as well as otherwise (1980, 79). The wealth of counterexamples and more recently the fiction of an external intervener who is free to redirect the neural pathways of my actions against my will (see Bishop 1989, chap. 4-5; McKann 1998, chap. 6), make the extreme dimensions of this task very plain. Whether or not the aim behind an agent's action is actually achieved always also depends upon the contingent circumstances (whether the golfing green is flat; whether the telephone number is reached), and because these causal influences are not predictable, they cannot be anticipated within an intention to act. The necessary guidance is therefore more interactive, the relationship between intention and result a recursive process, and not the same as a causal happening within the action (or, in the extended theory, within reflexive states of the agent). The correspondence between an intention and the result of an action alone is not sufficient; what is necessary is guidance by the agent during a sufficiently long part of the action, differentiated according to the type of action. A causal model for

26 Such proposals are included, amongst others, in Velleman 1992; Bratman 2000; Smith 2004. 
this condition is (or so it appears) neither possible nor in all probability interesting. $^{27}$

In line with the objection stemming from the everyday relevancy of causal explanations of action already noted, Hornsby also objects to shifting agency into complexes of higher-order intentions and action strategies (Hornsby 2004a, 14), as she thinks that most agents do not possess such higher-order states when acting. Quite possibly, but under which conditions is agency appropriate, aptly expressing action activity? Hornsby does not give a clear answer to this. If not from the basic premises of the standard theory, why else be a maximalist, extending an action to include the characteristics of the agent? It seems to me that the abovementioned motive of the maximalists is worth considering, even under non-causalist premises: in order to permit his purpose to become an action, the activity of an agent must be 'rational' to a certain extent, which is hardly possible without the agent himself being 'rational'. "To a certain extent" is a vague precept, the vagueness of which might lead to slightly overstretched activity conditions in order to be met by many of our particular actions. But why should such conditions not be idealised in their formulation and then be mitigated in order to match our everyday understanding?

A necessary connection thus postulated between actions and rational agency seems to be directly contradicted by the objection that even irrational actions are obviously still actions. (In a similar manner, one could also contradict other forms of normative action, like autonomous or authentic actions, by pointing out that compulsive or alienated actions do not lose their action character.) And yet the notion that all actions are first and foremost actions, which then have the cited normative qualities added on, is wrong. Far more, some actions are normatively thin actions (my arm going up), and other actions are only possible because of their thick normative qualities (greeting, heeding a stop sign). If the standard theory only captured normatively thin actions, it would be inappropriate to the vast majority of human actions. The maximalists therefore choose to adopt the correct strategy, albeit partly from problematic motives, by taking normatively more complex agent conditions into account. In

27 The condition of guidance stems from Frankfurt 1978. An informative discussion of the various proposals for a solution regarding deviant causal relationships is provided by H. McCann (1998, chap. 6). However, his own postulate of 'intrinsically actional' volitions (112) is just as ad hoc as his criticised attempts at solution put forward by the causalists. 
contrast to Hornsby's objection of expecting too much, this really could be interpreted as just that: more complex actions being taken into account. With the obvious wealth of different interests in actions, the assumption that all actions are first and foremost actions per se, independently of particular interests in them, becomes obsolete. Far more, actions are dependent upon interests and context, and this makes them differ.

Frankfurt's classic differentiation between the wanton and the selfgoverned agent can both illustrate this and diffuse any suspicion that the normative conditions might be too complex. The wanton individual (who converges with the agent in the standard theory) acts in order to satisfy his desire, but has no control over that desire. In contrast, the agent with a second-order desire which lends authority to his desire to act, acts in a self-governed manner; he not only controls the course of his action, as called for by Frankfurt (1978), but also its motives. ${ }^{28}$ If human actions are not to be reduced to the level of behaviour, a certain degree of higher-order governing of actions is definitely necessary-a circumstance which is neglected in the standard theory, in particular due to a concentration on examples which are too simplistic. It is one thing to explain the difference between raising my arm and my arm going up (Davidson 2004, 101), and quite another to do justice to typical human actions with all their various potential for failure.

If, from this point onwards, we refer to the 'maximalists' as 'normative actoralists', we can then divide them into two categories: action-orientated actorialists and person-orientated actorialists. This distinction roughly corresponds to the distinction between ethics of action and of virtue, an attempt to set moral standards primarily for individual actions or primarily for agents. The action-orientated actorialists would like to describe individual action as normatively appropriate via agent conditions, whereas the agent-orientated actorialists would only like the agent and actions to be characterised indirectly. The latter dedicate themselves to this extended task not from an abitrary interest in agents, but because they regard the first attempt as unsuccessful. With his proposals regarding second-order desires and volitions, Frankfurt was primarily an action-orientated actorialist. The criterion of being satisfied now no longer refers solely to current states of

28 Although Frankfurt (1978) only demands tighter guidance for the formation of an action, even attributing this ability to spiders, 'guidance' is obviously a typically human capability which even extends to the motives behind an action. 
the agent (like desires), but also in the longer term and cross-situationally to operative dispositions of the agent. ${ }^{29}$

In wishing to explicate the active quality of the term "agency" by means of a directly given agent state, the action-orientated actorialists find themselves in the same difficulties as Prichard and other voluntarists: problems of circles and regresses, or ad hoc postulates of intrinsically active volitions' or 'volitional necessity' in order to circumnavigate these problems. In contrast, the agent-orientated actorialists view agency as anchored in dispositional characteristics of the agent, such as plans to act, 'self-governing policies' (Bratman), or a manner of action directed towards longer-term goals. ${ }^{30}$ In the face of the destructive circularity of the first position, the only option is clearly to follow Bratman, who shifts the internal problem of the insoluble difficulty of complete governing of action to more general, personal characteristics, and become an agentorientated actorialist.

Of the three extension tendencies the standard theory has so far been described as producing-following on from a missing concept of intentions, insufficiently normative practical reasons and the blind spot of agency-this movement away from action activity towards the normatively reconstructed agent is the most important in several respects, albeit the one which is least clear at present. Firstly, the agent comprehended temporally and normatively is capable of incorporating both the temporalised concept of intentions and the concept of external reasons, thus providing a suitable framework for the transformation of the standard theory outlined here. Understanding the agent temporally, Bratman $(1999$; 2007) in particular has managed to bridge the intentions behind an individual action and the agent conscious of his temporal identity. Secondly, the developments described above have taken the conflict between normativity and naturalism/causalism, which has been

29 "Satisfaction is a state of the entire psychic system - a state constituted just by the absence of any tendency or inclination to alter its condition." (Frankfurt 1999, 104)

30 "We try to solve the problem of subjective normative authority, and to say what constitutes the agent's deliberation, by appeal to higher-order intentions, plans, and policies, about which desired ends to treat as reasons in motivationally effective deliberation. This seems a promising strategy in part because such higher-order intentions, plans, and policies have, as a matter of function, tight connections to the temporal extension of agency. That is why they are candidates for attitudes that, because their role in our agency, can speak for the agent." (Bratman 2001, 101) 
present in the standard theory from the outset, and elevated it to a higher platform, but without solving it. Following a premise of this overview, however, no other reaction to the problem of analysis in the confrontation with elementary concepts is possible than that of expanding the field of vision and to observe local problems in the light of ever more extended conditions. ${ }^{31}$

This premise is confirmed by the observation that the described development opens up several key questions. First, concerning the extent of the temporality of the agent: what temporal abilities does an agent have to possess in order to be a 'complete' agent? What would minimalism and maximalism mean in this context? Second, concerning the connection between motives and (external) reasons: to what extent does the agent participate in the social 'space of reasons', and how motivating are these reasons? Third, concerning interpretations of agency by means of 'selfgoverning policies': to what extent does every action already embrace the conditions (even if not their realisation) of autonomous or authentic action? In other words, to what extent is being autonomous and authentic not peculiar to especially complex actions, but already contained within the basic model of action, merely overlooked by the standard theory to date?

\section{The Extended Context: Basic Attitudes, Policies, Practices}

The action theorists referred to above as minimalists, and others besides, could view the described tendencies of the extended field of action less as a profound analysis of actions and more as a transition to other themes. Indeed: social plans for action, external reasons and actorial action strategies might still be necessary as conditions underlying individual actions, but do they not kick off a never-ending series of possible action/ context relation pairs, with the threat of losing the real constitutive conditions for individual action, and thus its 'essential' concept? Do the maximalists not really dissolve the concept of acting rather than explicating it further?

31 For this reason I have my reservations about Bratman's (2001, 102-3; 2002) attempts to eliminate the dreaded circle by explaining the activity of actions through agency by means of conceptual distinctions. Why is this circle to be abolished if the concepts of action and the agent cannot be perceived in mutual exclusion in the first place? 
This problem of the relationship between action and context, bearing in mind the different concepts of 'context', and of the distinguishability of actions and context, rears its head when the event-causalistic ontology of the standard theory is definitively discarded and all actions are comprehended as "orthonomous" (Smith 2004), with different dimensions of 'orthonomy' and different types of interaction between the agent and the action context. Making a distinction between actions and their context is both legitimate and necessary in order to study the type of interaction between the two. But if, correcting Davidson's original abstraction, ${ }^{32}$ actions only appear as normatively qualified actions in the world, two things seem to be necessary. First, the different dimensions of action normativity need to be distinguished and their connection more closely observed. A normative theory of actions would relate these dimensions to each other systematically. Second, actions need to be distinguished from their normatively reconstructed social conditions of origin-their socio-normative context. If actions are not ontologically self-involved pieces, but typical, average, widespread actions, then philosophical action theory has, just as the sociological action theory based on M. Weber's ideal types always has, to portray 'ideal' actions. Typical actions could be important to the extent that they are a prerequisite to all descriptions of particular actions. The particular actions of individual agents may not always meet the normative demands made of actions, and yet confirm precisely this normativity in the process. Unintentional, irrational, compulsive, conventional action can only fail in different dimensions if it is evaluable in these different dimensions of normativity.

Be that as it may, more important than a collective category for the actions discussed specifically by philosophers are lists of the various practical functions within and beyond actions. Which psychological functions must an agent fulfil in order to have control over his actions? And which normative functions do agents and actions have to fulfil

32 "A reason rationalizes an action only of it leads us to see something the agent saw, or thought he saw, in his action-some feature, consequence, or aspect of the action the agent wanted, desired, prized, held dear, thought dutiful, beneficial, obligatory, or agreeable. .... The word 'attitude' does yeoman service here, for it must cover not only permanent character traits that show themselves in a lifetime of behaviour, like love of children or a taste for loud company, but also the most passing fancy that prompts a unique action, like a sudden desire to touch a woman's elbow." (Davidson 1980, 3-4; also 87) 
before it is possible even to speak of such psychological functions? ?3 $^{33}$ Against which normative background are they possible? Which normative roles can an action play, which of these are the most important and how do they relate to one another? Which tasks do actions typically have to fulfil? These questions are almost impossible to address unless they are read such that the (partly intentional, partly unintentional) function of actions results within the framework of typical contexts, such as in interaction with other people, within actions plans or previous histories, within the framework of projects, etc. The internal and external functions of actions can, however, only be mutually related through the typical normative dimensions of actions. ${ }^{34}$ A classification of action-constitutive contexts can thus only be arrived at by distinguishing different normative functions of actions.

Four such dimensions have already emerged more or less clearly in the course of these remarks, intentions, reasons, self-governing and authenticity. ${ }^{35}$ Intentions include commitments and are thus embedded within a normative space of reasons; reasons are generally accessible states of affairs and thus elements within a social space of reasons, stabilised by a background of shared assumptions which needs to be accepted; selfgoverning is higher-level agency, which in turn requires external and lastingly potent proofs and responses because it cannot succeed on its own strength alone; authenticity could be rendered as loyalty to one's own characteristics and personal history. Whereas the first two

33 For the first functional question see Bratman 2001, 92, for the second see Santiago 2005, 92. Santiago distances himself from purely psychological functions, as discussed by Bratman, but himself suffers from a normatively dubious term of "social roles" and "social contexts".

34 Single actions as part of social or cooperative actions are therefore merely the visible manifestation of the normative dimensions which have always been given with human actions; they are, as it were, second-level social actions, preceded by non-cooperative actions as first-level social actions. For social action in this manifest sense of the second level see Tuomela 1995; Bratman 1999, essays 5-8; Stoutland 1997. In my opinion all three cleave to an individualistic intuitionpartly in conflict with their intentions-in that they do not explain the normativity of individual actions sufficiently out of the very social relationships they try to catch. In contrast see Brandom: "Both selves and communities are normative structures instituted by reciprocal recognition." (2002, 217)

35 Prudence and morality are further normative dimensions, yet the difference between the two is controversial. For a critical treatment of their relation to actions see Enoch 2006. Both dimensions are less general than those cited so far, with it being easier to imagine imprudent and immoral agents than aimless, irrational, compulsive and self-denying ones. 
dimensions take precedence within action theory, the difficulty of distinguishing rational and self-governing autonomous action is in itself evidence of how one-sidedly traditional these associations are.

Minimalists and maximalists concerning agency are currently having difficulty making a distinction between action per se and autonomous action. While some authors move without hesitation from one term to the other (Velleman 1993; Frankfurt 1999), present analyses largely reduce autonomous action to action per se because they tend to fall back only on those elements which, at best, promote the elementary characteristics of action up several levels. ${ }^{36}$ The consequence of this can only be either to back out of the concept of autonomy or to name external conditions for autonomous action which are not valid for intentional action. Within the framework of a socio-normative view of actions these conditions could consist in the way in which the agent behaves towards others: whether in typically autonomy-relevant situations, such as the assumption of responsibility, reaction to practical and theoretical problems, reaction to questions regarding his own motives and reasons for acting, he demonstrates the corresponding skills or not.

The significance of different dimensions of the normativity of actions extends the focus upon actions, as does comprehension of actions as typical actions. Depicting actions as typical also presumes a role they play in connection with other typical human characteristics and happenings, human primary goods or practices. The roles played by actions in individual and collective knowledge, in personal and extrapersonal history, in a narrower and broader society are surely three types of action context, the significance of which may be obvious for our actions in general terms, but difficult to follow in detail. The mutual dependencies of cognition and action, the entanglement of doing and experiencing within the biographical framework, the dependencies between individual and social action - these aspects are surely discussed in many disciplines of the arts and social sciences, but fatally they are largely and systematically ignored in philosophical action theory so far. And so much the worse for that, because if the development of action theory pursued in this overview is correct, normatively differentiated action theory is impossible without a thorough study of these contexts.

36 See similarly Buss 2007, who especially criticises the explanation of autonomous action by means of rationality and reflexivity. In my opinion, Buss' own externalistic analysis of autonomous action refers more to authentic than autonomous action. 
Holism within semantics means comprehending the meaning of individual sentences in connection with all the other sentences of a language. In terms of rational argumentation holism means comprehending the quality of an argument in connection with all the other arguments which are possible and relevant. The extension of 'relevant' contexts for arguments improves our understanding of these arguments, the extension of 'relevant' contexts for sentences our use of these sentences. What is true of sentences and arguments cannot be false for actions for the simple reason that the latter are only possible in close connection with the former. Up to his latest statements (2001), however, Davidson tried to balance the importance of the event-causal form of actions and their normative role, instead of conceding priority to the latter. By doing this he unfortunately distanced his holism of meaning and knowledge from the theory of action. All the more reason for us today to bring the long tale of the standard theory of action to a happy end by closing it forever and replacing it with a normative, contextualised and holistic theory of action.

\section{Articles and Comments in the Present Volume}

Most of the articles and comments in this book stem from a conference entitled "Action in Context", organised by the editor in Zurich in April 2005, but some have been added afterwards. To start, P. Hacker's contribution serves to bring home the far-reaching spirit of action theory which dominated recent philosophy prior to its 'Davidsonian revolution'. The relations between thinking and acting, perception and moving bodies, intentions and autonomy which are skilfully handled by Stuart Hampshire in Thought and Action could serve as a programmatic contrast to the certainly more detailed but sometimes also too self-sufficient later debates. On the other hand, Hampshire's and Hacker's picture of actions and agents somewhat falls behind the externalist analysis of actions depicted thus far. It does focus on non-causal intentionality, but presentation of the agent draws narrowly on purely cognitive and psychological concepts. The agent commands special intentional knowledge with regard to his actions, is active in a special way with regard to his convictions and has rationality and autonomy at his disposal purely by being himself. This slightly superhuman concept of the agent contrasts strangely to the equally Spinozistic concessions to body and causality. In his programmatic approach to thinking and acting Hampshire ultimately 
refrained from attempting a synthesis of the two phenomena, but the sheer scope of his agenda is still worthy of note today.

The following articles and comments included within this book address three discussions outlined in this introduction: the appropriateness of the desire-based concept of reasons and the ontology of single actions (I. Acting for Reasons), the significance of action within the extended context of practical intentions, personal self-perceptions and life-stories (II. Action, Persons and Life), and the relationship between action and cognition (III. Action and Epistemology).

The first round is dominated by the controversy between representatives of the factive theory of reasons and advocates of the standard theory. F. Stoutland defends the external or factive concept of reasons with regard to the difficulties particularly arising from a differentiation between explanatory and normative reasons. In his opinion, causal explanations, like those attempted by Fodor and Audi, are not tenable because their causal claims are strongly implausible. Davidson's subjective version of reasons is for Stoutland too weak to describe rational acting. According to him, Davidson's response to the requirements of understanding and causally explaining an action comes at the expense of a complete isolation of actions from their normative environment and thus also from normative reasons. With regard to the problem already observed by Dancy and Bittner, concerning how to explain the erring agent from the factive concept of reasons without recourse to subjective reasons, Stoutland contributes an additional attempt at a solution which appears to unite Dancy's and Bittner's proposals. In his opinion, explanatory reasons are always intentional reasons without a factual claim to truth and fulfil the same explanatory function as the belief of an agent, without that belief explicitly needing to be mentioned.

The starting point of T. Schmidt's comment is in turn the weak point of factive reasons, i.e. such contraintuitive "explanations invoking a false explanans". In an overview he weighs up the strengths and weaknesses of the proposals by Stoutland, Smith and Bittner and comes to the conclusion that a semantic analysis could be a substitute for the assumption of non-existent states of affairs in which, as with penalties pronounced by a referee, existing or non-existing states of affairs are replaced by normative decisions. Schmidt would like to retain Dancy's and Stoutland's explanations in principle, but also to replace their ontology of non-existing states of affairs with explanations using normative authority. Normatively authorising explanations would then render Stoutland's recourse to non-factive states of affairs unnecessary. 
Schmidt, however, also brings a contrast into play which reduces the usability of his example: a player's foul in the eyes of the referee and the 'real' foul. As long as 'real' fouls exist without a normative decision, then it seems non-factive reasons also exist.

M. Alvarez points out the close connection between the claim of causal explanations of action and Davidson's hypothesis that reasons for action are psychological states. In contrast, the claim to causality is not the pivotal point of the factive concept of reasons and may even be excluded by it. Against the standard theory Alvarez attempts to show that the interest in causality is hardly compatible with normative and motivating reasons, and is indeed suppressed by the latter. As a further advocate of factive reasons, she criticises the identification of desires with motivating reasons and, following on from this, the identification of motivating reasons with psychological states. Unlike Dancy, Stoutland and Schmidt, and similarly to Smith and Bittner, Alvarez tends to view normative and explanatory reasons in the light of erring agents as disjunctive, and she wants to accept psychological states (beliefs, desires) as explanations only. But even in these explanations she believes that conceptual connections between the elements of explanation (desires, beliefs, actions) dominate, in contrast to empirical generalisations of a typical Humean causal explanation. According to Alvarez, explanations of reasons are teleological explanations to which no action-relevant information can be added by causal relations.

That the standard theory has not lost any of its attraction today is validated by $P$. Hübl's critique of Alvarez. In his opinion, facts as reasons necessarily have to be connected to an agent's actions-via his psychological states. Reasons become reasons of the agent (as opposed to reasons for the agent) when he is conscious of them. According to Hübl, Alvarez' teleological explanations cannot escape the distinction that an agent pursues either actual or fictive goals, that he has actual or apparent reasons. This distinction cannot be formulated without reference to psychological states. One consequence of Alvarez' relinquishment of causality is also illuminated by Hübl. If reasons are facts beyond psychological states, is a story connecting facts and agents then totally impossible? "It is hard to see how reasons could be related to our moral and juridical practice of blame and punishment, if no causality were involved." (this volume, 128)

While some advocates of factive reasons, like Stoutland and Alvarez, tend towards weakening the relevance of causality in actions and explanations of action with a new version of the logical connection 
argument, others hold that an explicitly causal analysis of action is necessary but has to be, in contrast to the standard theory, a version of agent causality. $R$. Stout thinks that the chain-model of causality needs to be replaced by a process model orientated towards Aristoteles' qualitative concept of causality, with causality and acting in some form of convergence. At the centre of Stout's proposal is the notion that causality has in each case to be qualified by a causal mechanism because only through such specifications can deviant relationships in causal statements be eliminated. But how, in the case of actions, is this mechanism to be picked out if it is to be distinguished from event-causally dissolvable 'mechanisms'-like the wind drying the washing? Stout's proposal, not unlike Aristotle's, draws upon the mechanism of practical rationality. An agent attempts something with intention when that something happens due to a mechanism of practical rationality embodied in the agent. Practical rationality is then simultaneously qualitative agent causality.

J. Bishop's reaction, perceiving in Stout's rationality mechanism only a conceptual and not an ontological analysis of agency, shows how not even Stout's proposal can evade the classical criticism of Aristotle's notion of a 'substance causality'. Bishop tentatively proposes the coexistence of a process causality of rational action control through the agent, and an event-causal view of that same control in the 'real world'. On the one hand, this proposal is a reaction to the difficulty of using Stout's formulation of the rational agent mechanism really to grasp causality and not just a rational structure, for example the Practical Syllogism. On the other hand, Bishop's proposal of different levels involves new difficulties and would certainly not be compatible with the claim of mechanisms to be real. For now this discussion therefore has to end in a stalemate.

Unlike the authors of the two preceding contributions, T. Lekan is of the opinion that an analysis of actions should not begin with the connection between reasons for and causes of individual actions, but with a look at socio-psychological contexts, orientated towards the concept of habits. In the tradition of Dewey's behavioural theory, Lekan reminds us of a repertoire of concepts and descriptions which, in the present analytic theory of action, has largely been put to one side. Dewey's and Lekan's vocabulary is aimed explicitly against a 'Cartesian agent' and it endeavours to reverse the direction of dependencies. Given the breadth of this attempt, Lekan's contribution to this book is more of a programmatic outline than systematic proof of the fruitfulness of this theoretical reversal. 
Regarding the breadth of the term "habit", $N$. Anwander's differentiation between social practices and individual dispositions is helpful. The dependency of our action on socially widespread manners of acting, on a pregiven logic, is far greater than we usually think. Nevertheless, the scope for individual behaviour with regard to given practices is in itself so great that Anwander does not view the predominant philosophical interest in actions per se, as opposed to particular individual actions, as in any danger. Social practices are not merely acted out, but interpreted individually. A similar thing is true of habits as individual dispositions. Dispositions, practices and reasons are mutually interdependent, the first two actually entrenching reasons more than suppressing them. According to Anwander, the different currents in action theory are on a convergence, not a collision course. Pragmatism would bring a particular social enrichment to the external conception of reasons, not suppress it.

How do the premises of the standard theory stand up when confronted with the Kantian notion of moral will, with the ontological problems of personal identity or the question of what makes a life-story a reasonable unit? These are the questions which Velleman/Roughley, Cuypers/Slors and Bittner/Baumann take up in the second part of this book. D. Velleman raises the question of what an agent's ability to will is good for. According to Velleman, there are some difficulties regarding this question within Bratman's planning theory. Not all intentions are subordinate to the pragmatic function of being fitted into action plans. Many actions are not planned in advance, instead resulting spontaneously within a situation. Also, in Bratman's model, intentions are too weakly connected with a self-knowledge of the agent, too closely linked to a narrowly comprehended pure volition, meaning that they cannot fulfil the pragmatic function of action coordination which Bratman alleges. From this Velleman concludes that a pragmatic-functional explanation of intentions and volitions is missing the point altogether, and that the 'myth of intelligent design' of the will should be replaced by a 'myth of chance'. Just as Mediaeval architects invented the spandrel by chance, the will could also have its origins in chance and consequently not be completely subordinate in its functionality to the rational optimisation of desires_-something necessarily to be assumed in the planning theory. Velleman, following on from Kant, views the will as an irreducible source of self-knowledge and conflicts, from which desires are systematically shaped, but can also be arbitrarily shed.

In his comment, $N$. Roughley suggests that Bratman's pragmatic function of planning optimisation should be taken as an abstract- 
theoretical explanation, meant neither conceptually nor evolutionistically, and not in need to cohere directly with the intentions of particular agents. Like Velleman, Roughley takes proximate intentions to be inexplicable through distal intentions, and thus believes differing explanations to be appropriate. In contrast, Roughley remains reticent about Velleman's attempt to explain intentions through cognitive attitudes and, further, through the 'deep desire' to know what one is doing postulated by Velleman. Bratman's non-cognitive theory appears to him to be less speculative and therefore preferable.

$S$. Cuypers reports what has been achieved in the debate on 'personal identity' by analytical philosophers to date as a stalemate between the empiristic and the Cartesian tradition. Whereas the Cartesian tradition could explain personal responsibility but is metaphysically problematic, the empiristic tradition, especially in the shape of Parfit's theory, leads to unacceptable practical consequences, to the reduction of human beings to raindrops, as Cuypers puts it. In his attempt to develop a less paradoxical concept of personal identity, Cuypers draws upon Strawson's famous view of persons as irreducible, 'logically primitive' units of body and mind, and especially upon his portrayal of persons as agents with intentions and reactive attitudes, embedded in a social world of co-agents. Taken further, Cuypers views these irreducible persons as agents within Davidson's rationality holism, in which agents' manners of acting prove them to be temporally identical. All paradoxes and practical absurdities of the metaphysics of persons could be avoided, according to Cuypers, if persons and their characteristics were grasped from the premise of their prevailing existence as agents.

M. Slors wishes less to criticise Cuyper's plea for a 'logical personalism' and more to convey support through the neurosciences. He tries to show that Strawson's hypothesis of the irreducibility of persons was directed less at the metaphysical and more at a 'descriptive dualism', as anchored in everyday speech. Descriptive dualism has to be scientifically corrected, not philosophically. According to Slors, current research in the neurosciences provides stronger confirmation of personalism than the metaphysical debate.

Cuypers believes narrative identity to be a more particular, existential form of agent identity, and he would have little difficulty connecting the role of acting with the biography of a person and his or her 'life'. From the point of view of its actorial personalism, a human life would have to consist essentially in a number of actions. R. Bittner believes this view to be wrong, seeing its philosophical origins in the Sophists' conviction of 
the teachability of virtues and in Aristotle's synthesis of virtue and responsibility. Unlike the Sophists, he believes that virtues at best 'grow' inside us, not that we actively control them. What we achieve-more or less by chance-as 'deeds' or results is crucial, not our governing of actions. This scepticism towards the agent extends critically to the notion that an individual life could be given a direction or an aim. Rather, our lives lie beyond our activities and are best observed when we are dead. The same is principally true of what Bittner thinks to be the most suitable way of dividing up our lives, namely into units which he calls 'stories', but which he refuses to define. Stories are pieces of individual history, within which responsible action is possible at selected times, but without the ability to control their entirety. Bittner could agree to the idea of a 'narrative identity', but not to a personal identity as one of agents. Persons find themselves in the imponderabilities of the stories absorbing them.

Constitutive of Bittner's scepticism towards the relevance to life of actions is a distinction between the perspective of the agent and that of the spectator. In his comment H. Baumann criticises Bittner's application as too sweepingly exclusive. In acting, agents are often aware of their role from the spectator perspective, our conventional understanding of action always permitting a certain degree of passivity when acting - in contrast to Bittner's tendency to assume a strict opposition in acting between activity and passivity. Furthermore, a swimmer is aware of being carried by the waves and perceives his action as facilitated by this, not prevented by it. Only if the untenable reductive view of acting as pure activity is relinquished can certain forms of passivity acquire their actorial sense, namely in a perception as failures with regard to a particular action. Bittner could not give any plausibility to his concept of stories if he did not silently concede a logical priority of acting.

In the third part of this book, Hornsby/Saporiti, Leist/Schulte and Hookway/Hetherington address the mutual dependency of acting, beliefs and knowledge. J. Hornsby takes up the problem, already touched upon several times in this introduction, of the compatibility of reasons as beliefs and as factive reasons. She finds the attempts at synthesis by Ryle, Dancy, Smith and Stout all unsatisfactory in different ways. Perhaps Smith's attempt is the most reasonable, according to which normative and explanatory reasons are simply claimed to be mutually independent, but it is criticised by Hornsby for robbing explanatory reasons of their potential normative content. Without an internal connection between the two types of reason, explanations of actions are reduced to explanations of physical processes. Smith and Stout have attempted to eliminate this 
problem (also relevant to Bittner), yet unsuccessfully in Hornsby's view. Her own attempt at a solution draws upon an analysis of the distinction between belief and knowledge, according to which the difference between belief and knowledge consists in the adding-on of the given external state of affairs, without a difference in the subjective state of the believer. For Hornsby acting is always acting at least from a belief which can objectively become knowledge when the corresponding state of affairs applies.

In her comment K. Sporiti illuminates the predicament which moves Hornsby to find identical meaning of the term "reasons" in the explanatory and normative uses of the term, and arrives at the conclusion that both uses can exist harmlessly side by side without, as Hornsby believes, a puzzle emerging. According to Saporiti the rationality of the erring agent is not called into question when no factive reason corresponds to his subjective-justifying use of "reason". The two uses of "reason" are usually closely linked, meaning that, even in individual cases to the contrary, they can still be linked by presumption. Moreover, she believes Hornsby's proposal to be unworkable. A belief is not alleged knowledge, but simply a belief. Belief and knowledge are separated by the concept of being-true, which there would be no point in discovering if one could content oneself with the belief alone. The two concepts of justifying and explanatory reasons (and according to Saporiti some more uses of reasons besides) can exist side by side very well without the need for semantic bridges.

Like Hornsby, Leist/Schulte and Hookway/Hetherington are of the opinion that the theory of knowledge has to be connected with the theory of action, albeit in a somewhat different scope or context. A. Leist is interested in how cognition and action might be generally connected and criticises the traditional attempts to separate them, including in particular the ontological model of two 'directions-of-fit'. Instead of separating cognition and action, he proposes grasping cognition as a special form of action, as action with its own sort of action aims. With regard to this antiontological strategy, J. Schulte points out in his comment that not even the simplest concept of action can survive without the concept of environment, and that ontological prerequisites can therefore not be evaded altogether. He perceives the relationship between cognition and action less as a pair of opposites and more as components within a list, from which no serious problems are to be expected. In contrast to Leist's attempt to subsume all representative human characteristics within these 
two concepts, he sees in some passive behavioural forms a third possible category also belonging to a potentially open list.

Ch. Hookway embeds knowledge in the action process of inquiry and proves it to be irreducibly practical. Following Rorty, he views truth not as a goal of cognition, so that the classical search for truth would have to be replaced by a more particular logic of epistemological rationality. He sees this proposal confirmed in the appropriateness of a practical rather than theoretical answer to scepticism. St. Hetherington is less critical of Hookway's epistemic pragmatism, instead extending it by means of an analysis of the capabilities of knowledge linking propositional knowledge to non-propositional knowledge.

Action theory could surely play a more dominant role within the philosophical disciplines than is the case in their current agenda, this at least is amply shown by the papers in the second and third part of this book in particular. Actions are not objects, but a background for many things which, without reference to action, would not be sufficiently comprehensible. Whether, as suggested by the title of this introduction, actions themselves then also have to be comprehended differently, is a question which this book will undoubtedly help to examine. ${ }^{37}$

\section{Bibliography}

Anwander, Norbert (2002): "Intelligibilität und Normativität", in: Analyse \& Kritik 24, 231-248.

Bishop, John (1989): Natural Agency, Cambridge: Cambridge University Press. Bittner, Rüdiger (2001): Doing Things for Reasons, Cambridge: Cambridge University Press.

Brand, Myles (1984): Intending and Acting, Cambridge/MA: MIT Press.

Brandom, Robert (2002): Tales of the Mighty Dead, Cambridge/MA: Harvard University Press.

Bratman, Michael (1985): "Davidson's Theory of Intention", in: Ernest LePore/ Brian McLaughlin (eds.): Actions and Events, Oxford: Blackwell Publishers (also in Bratman 1999).

- (1984): "Two Faces of Intention", in: Philosophical Review 93, 375-405 (also in Bratman 1987).

- (1987): Intentions, Plans and Practical Reason, Cambridge/MA: Harvard University Press.

37 I would like to thank H. Baumann, R. Bittner, J. Schulte, F. Stoutland for critical comments and S. Kirkby for fundamental linguistic help. A shortened version of this introduction appeared in Deutsche Zeitschrift für Philosophie 55.4, 2007. Also I am grateful to the Swiss National Science Foundation for financial support. 
- (1999): Faces of Intention, Oxford: Oxford University Press.

- (1999a): "Practical Reasoning and Acceptance in a Context", in: Bratman (1999).

- (2001): "Two Problems about Human Agency", in: Proceedings of the Aristotelian Society 2000-2001, 309-326 (also in Bratman 2007).

- (2002): "Hierarchy, Circularity, and Double Reduction", in: Buss, Sarah/ Overton, Lee (eds.): Contours of Agency, Cambridge: Cambridge University Press, 65-85 (also in Bratman 2007).

- (2007): Structures of Agency, Oxford: Oxford University Press.

Buss, Sarah (2007): Autonomous Action: Self-Expression in the Passive Mode (Ms.).

Dancy, Jonathan (1995): "Why there is Really No Such Thing as the Theory of Motivation", in: Proceedings of the Aristotelian Society 95, 1-18.

- (2000): Practical Reality, Oxford: Oxford University Press.

- (2003): "Replies", in: Philosophy and Phenomenological Research 67, 468-490.

Darwall, Stephen (2003): "Desires, Reasons, and Causes", in: Philosophy and Phenomenological Research 67, 436-443.

Davidson, Donald (1970): "Agency", in: Davidson 1980, chap. 3.

- (1980): Essays in Action and Events, Oxford: Oxford University Press.

- (1984): Inquiries into Truth and Interpretation, Oxford: Oxford University Press.

- (1987): "Problems in the Explanation of Actions", in: Davidson (2004).

- (2001): "Aristotle's Action", in: Davidson (2005).

- (2004): Problems of Rationality, Oxford: Oxford University Press.

- (2005): Truth, Language and History, Oxford: Oxford University Press.

Donagan, Alan (1981): "Philosophical Progress and the Theory of Action", in: Proceedings and Addresses of the American Philosophical Association, 25-52.

Dretske, Fred (1988): Explaining Behavior: Reasons in a World of Causes, Cambridge/MA: MIT-Press.

Enoch, David (2006): “Agency, Shmagency: Why Normativity Won't Come from What is Constitutive of Action", in: Philosophical Review 115, 169198.

Frankfurt, Harry (1987): "The Problem of Action", in: American Philosophical Quarterly 15, 157-162.

- (1999): "The Faintest Passion", in: Frankfurt, Harry (1999): Necessity, Volition, and Love, Cambridge: Cambridge University Press, 95-107.

Hornsby, Jennifer (1980): Action, London: Acumen.

- (1993): "Agency and Causal Explanation", in: Heil, John/Mele, Alfred R. (eds.): Mental Causation, Oxford: Oxford University Press, 129-153.

- (2004a): "Agency and Action", in: Steward, Helen/Hyman, John (eds.): Agency and Action, Cambridge: Cambridge University Press, 1-23.

- (2004b): "Agency and Alienation", in: De Caro, Mario/Macarthur, David (eds.): Naturalism in Question, Cambridge: Cambridge University Press, $173-187$.

Hursthouse, Rosalind (1991): "Arational Action", in: Journal of Philosophy 88, $57-68$.

Malpas, Jeff E. (1992): Donald Davidson and the Mirror of Meaning, Cambridge: Cambridge University Press. 
McCann, Hugh (1991): "Settled Objectives and Rational Constraints", in: American Philosophical Quarterly 28, 25-36.

- (1998): The Works of Agency, Ithaca-London: Cornell University Press.

Mele, Alfred R. (1992): Springs of Action, New York: Oxford University Press.

- (2003): "Philosophy of Action", in: Ludwig, Kirk (ed.): Donald Davidson, Cambridge: Cambridge University Press, 64-84.

O'Shaugnessy, Brian (1980): The Will: A Dual Aspect Theory, Cambridge: Cambridge University Press.

Peacocke, Christopher (1979): "Deviant Causal Chains", in: Midwest Studies, $123-155$.

Raz, Joseph (1999): "Agency, Reason and the Good", in: Raz, Joseph (1999): Engaging Reason, Oxford: Oxford University Press, 22-45.

Ryle, Gilbert (1949): The Concept of Mind, Oxford: Oxford University Press. Santiago, John (2005): "Personal Autonomy: What's Content Got to Do With It?", in: Social Theory and Practice, 31.1, 77-104.

Scanlon, Thomas M. (1998): What we Owe to Each Other, Cambridge/MA: Harvard University Press.

Searle, John (2001): Rationality in Action, Cambridge/MA: MIT Press.

Seebaß, Gottfried (1993): Wollen, Frankfurt: Klostermann.

Smith, Michael (1987): "The Humean Theory of Motivation", in: Mind 96, $36-61$.

- (1994): The Moral Problem, Oxford: Oxford University Press.

- (1998): "The Possibility of Philosophy of Action", in: Bransen, Jan/Cuypers, Stefaan (eds.): Human Action, Deliberation and Causation, Dordrecht: Reidel, $17-41$.

- (2003): "Humeanism, Psychologism, and the Normative Story", in: Philosophy and Phenomenological Research 67, 460-467.

- (2004): "The Structure of Orthonomy", in: Hyman, John/Stewart, Helen (eds.): Agency and Action, Cambridge: Cambridge University Press, 165193.

Stoecker, Ralf (2002): "In den Zeiten, wo das Wünschen noch geholfen hat", in: Analyse \& Kritik 24, 209-230.

Stout, Rowland (1996): Things that Happen Because they Should: A Teleological Approach in Action Theory, Oxford: Oxford University Press.

Stoutland, Frederick (1985): "Davidson on Intentional Behaviour", in: LePore, Ernest/McLaughlin, Brian (eds.): Actions and Events, Oxford: Blackwell Publishers.

- (1986): "Reasons, Causes, and Intentional Explanation", in: Analyse \& Kritik $8,28-55$.

- (1997): "Why are Philosophers of Action so Anti-Social?" In: Alanen, Lilli/ Heinämaa, Sarah /Wallgren, Thomas (eds.): Commonality and Particularity in Ethics, London: Macmillan Press, 45-74.

- (1998): "The Real Reasons", in: Bransen, Jan/ Cuypers, Stefaan E. (eds.): Human Action, Deliberation and Causation, Dordrecht: Reidel, 43-66.

- (1999): "Intentionalists and Davidson on Rational Explanation", in: Meggle, Georg (ed.): Actions, Norms, Values, Berlin-New York: DeGruyter, 191-208. 
- (2001): "Responsive Action and the Belief-Desire Model", in: Grazer Philosophische Studien 61, 83-106.

Thalberg, Irvin (1985): "Analytical Action Theory: Breakthroughs and Deadlocks", in: Seebaß, Gottfried/Tuomela, Raimo (eds.): Social Action, Dordrecht: Reidel, 1-41.

Tuomela, Raimo (1995): The Importance of Us: A Philosophical Study of Basic Social Notions, Dordrecht: Reidel.

Velleman, David J. (1992): "What Happens, When Someone Acts?", in: Mind 101, 461-481 (reprinted in: Velleman 2000).

- (2000): The Possibility of Practical Reason, Oxford: Oxford University Press

Wallace, R. J. (2003): "Explanation, Deliberation, and Reasons", in: Philosophy and Phenomenological Research 67, 429-435.

Williams, Bernard (1981): "Internal and External Reasons", in: Williams, Bernard (1981): Moral Luck, Cambridge: Cambridge University Press, 101 113.

Wilson, G. (1980): The Intentionality of Human Action, Amsterdam: North Holland.

- (1985): "Davidson on Intentional Action", in: LePore, Ernest/McLaughlin, Brian (eds.): Actions and Events, Oxford: Blackwell Publishers.

- (2002): "Action", in: Stanford Encyclopedia of Philosophy. 
